\title{
The Scavenging Effect of Myoglobin from Meat Extracts toward Peroxynitrite Studied with a Flow Injection System Based on Electrochemical Reduction over a Screen-Printed Carbon Electrode Modified with Cobalt Phthalocyanine: Quantification and Kinetics ${ }^{\dagger}$
}

\author{
Ioana Silvia Hosu $^{1, *(\mathbb{D})}$, Diana Constantinescu-Aruxandei ${ }^{1}\left(\mathbb{D}\right.$, Florin Oancea ${ }^{1}(\mathbb{D})$ and Mihaela Doni $^{2, *(\mathbb{D})}$ \\ 1 Bioproducts Department, National Institute for Research \& Development in Chemistry and \\ Petrochemistry-ICECHIM, 202 Spl. Independentei, Bioproducts, Sector 6, 060021 Bucharest, Romania; \\ diana.constantinescu@icechim.ro (D.C.-A.); florin.oancea@icechim.ro (F.O.) \\ 2 Biotechnology and Bioanalysis Department, National Institute for Research \& Development in Chemistry and \\ Petrochemistry-ICECHIM, 202 Spl. Independentei, Sector 6, 060021 Bucharest, Romania \\ * Correspondence: ioana.hosu@icechim.ro (I.S.H.); mihaela.badea@icechim.ro (M.D.); Tel.: +40-213-163-063 (M.D.) \\ + This article is the extended version of our paper: Hosu, I.S.; Constantinescu-Aruxandei, D.; Oancea, F.; \\ Doni, M. Studying Modified Screen-Printed Carbon Electrodes and a Flow Injection Analysis System. \\ In Proceedings of the 1st International Electronic Conference on Biosensors, 2-17 November 2020.
}

check for

updates

Citation: Hosu, I.S.;

Constantinescu-Aruxandei, D.;

Oancea, F.; Doni, M. The Scavenging

Effect of Myoglobin from Meat

Extracts toward Peroxynitrite Studied with a Flow Injection System Based on Electrochemical Reduction over a Screen-Printed Carbon Electrode Modified with Cobalt Phthalocyanine: Quantification and Kinetics.

Biosensors 2021, 11, 220. https:// doi.org/10.3390/bios11070220

Received: 13 June 2021

Accepted: 29 June 2021

Published: 2 July 2021

Publisher's Note: MDPI stays neutral with regard to jurisdictional claims in published maps and institutional affiliations.

Copyright: (C) 2021 by the authors Licensee MDPI, Basel, Switzerland. This article is an open access article distributed under the terms and conditions of the Creative Commons Attribution (CC BY) license (https:/ / creativecommons.org/licenses/by/ $4.0 /)$.

\begin{abstract}
The scavenging activity of myoglobin toward peroxynitrite (PON) was studied in meat extracts, using a new developed electrochemical method (based on cobalt phthalocyanine-modified screen-printed carbon electrode, SPCE/CoPc) and calculating kinetic parameters of PON decay (such as half-time and apparent rate constants). As reactive oxygen/nitrogen species (ROS/RNS) affect the food quality, the consumers can be negatively influenced. The discoloration, rancidity, and flavor of meat are altered in the presence of these species, such as PON. Our new highly thermically stable, cost-effective, rapid, and simple electrocatalytical method was combined with a flow injection

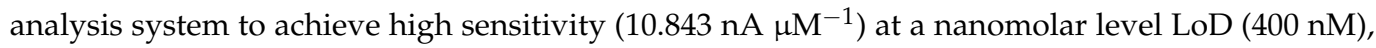
within a linear range of 3-180 $\mathrm{MM}$. The proposed biosensor was fully characterized using SEM, FTIR, Raman spectroscopy, Cyclic Voltammetry (CV), Differential Pulse Voltammetry (DPV), and Linear Sweep Voltammetry (LSV). These achievements were obtained due to the CoPc-mediated reduction of $\mathrm{PON}$ at very low potentials (around $0.1 \mathrm{~V}$ vs. $\mathrm{Ag} / \mathrm{AgCl}$ pseudoreference). We also proposed a redox mechanism involving two electrons in the reduction of peroxynitrite to nitrite and studied some important interfering species (nitrite, nitrate, hydrogen peroxide, dopamine, ascorbic acid), which showed that our method is highly selective. These features make our work relevant, as it could be further applied to study the kinetics of important oxidative processes in vivo or in vitro, as PON is usually present in the nanomolar or micromolar range in physiological conditions, and our method is sensitive enough to be applied.
\end{abstract}

Keywords: electrocatalysis; peroxynitrite; flow injection analysis; meat extracts; myoglobin; cobalt phthalocyanine; electrochemical reduction; screen-printed carbon electrode; amperometric detection; decay kinetics

\section{Introduction}

For the food industry and for the consumers, it is very important to monitor the quality and freshness of raw meat. Different factors are a sign of meat alteration (e.g., discoloration, rancidity, alteration of flavor) [1-3]. One pathway of alteration is the scavenging activity of myoglobin toward nitro-oxidative species (such as peroxynitrite, PON). For example, the formation of metmyoglobin can alter the flavor due to lipid and protein oxidation [4]. The lack of metmyoglobin $\left(\mathrm{MbFe}^{3+} \mathrm{OH}_{2}\right.$ or metMb) reducing enzymatic systems in meat 
after slaughter determines the irreversibility of the oxidation processes of myoglobin [5]. The color changes are a sign of these processes, and some possible oxidation pathways are described in Figure 1 [6]. The aspect of meat, by itself, has a great impact on consumers, and the impact on the food industry is huge. Adding nitrites to the raw meat helps keeping the pink color of the meat, as $\mathrm{NO}$ (nitric oxide) can bind to the iron ion in a similar way as oxygen molecule does. Nitrites and nitrates are also two of the decomposition compounds of peroxynitrite. Distinguishing between these species is important for meat quality.

The detection of peroxynitrite, being a short-living ROS in biological samples, is a big challenge that scientists still try to solve nowadays. Even if there are different methods of detection presented in the literature, most of them rely on indirect methods after the formation of secondary species. Forming different species, such as 3-nitrotyrosine, that can be detected by immunochemical or chromatographic techniques, or oxidizing different probes with peroxynitrite, further to be detected with fluorescent and chemiluminescent methods, are the usual methods [7]. The problem is that the selectivity toward peroxynitrie is not assured using these methods, as other ROS/RNS species could give the same response. Other usually used methods are high-performance liquid chromatography, UV-Vis absorbance spectroscopy, electron spin resonance, and electrochemistry [8]. These methods usually use antioxidants such as resveratrol, polyphenols, or catechins [3], especially in batch analysis, but also using flow injection analysis, for example by injecting antioxidants that can quench the peroxynitrite [9]. The microfluidic injection analysis presents different advantages such as the presence of laminar flow with no dilution effects, necessity of low volume of analyte (lower than $150 \mu \mathrm{L}$ ), miniaturization, the possibility of real-time continuous monitoring (process control), faster and more sensitive response, or the possibility of automated processes [10].

Electrochemistry uses usually low-cost instrumentation, has fast response time, and can be coupled with online analysis. Electrochemical methods are a better alternative than the usually used methods as they can assure direct, label-free, specific, real-time measurements. Different electrochemically active matrices are described in the literature, such as polymeric films (based on porphyrins, metal phthalocyanine, and/or conducting polymers) hybridized or not with graphene [7,11-16]. Only very few reports present the batch reduction (or oxidation at low potential) of peroxynitrite using a chemically modified electrode (presented in Table 1). Ligands based on extended $\pi$ conjugated systems can create coordinative chemical bonds with different metals and act as good electrochemical mediators for different redox processes, even nowadays. Phthalocyanines (PCs) are part of this class, and due to different oxidation states of various metallic centers and high conductivity, they are a good platform for the detection of oxygen/nitrogen reactive species [11] or other molecules [17]. PCs are not toxic and have high thermal resistance and are quite stable at room temperature, assuring the stability of the biosensors in time. Except for the metallic centers, the ring-based redox processes may also influence the catalytical activity.

Table 1. Literature study of the developed sensors used to detect PON via electroreduction.

\begin{tabular}{|c|c|c|c|c|c|}
\hline Biosensor & $\begin{array}{l}\text { Potential } \\
\text { (V) }\end{array}$ & $\begin{array}{l}\text { Sensitivity } \\
\left(\mathrm{nA} \mathrm{mM}^{-1}\right)\end{array}$ & $\begin{array}{l}\text { LOD } \\
(\mathrm{nM})\end{array}$ & $\mathrm{pH}$ & Ref. \\
\hline $\begin{array}{c}\text { Microelectrode Pt/Mn-pDPB } \\
\text { (manganese-[poly-2,5-di-(2-thienyl)-1H- } \\
\text { pyrrole)-1-(p-benzoicacid)]) coated with PEI } \\
\text { (polyethyleneimine) }\end{array}$ & 0.2 & 157.0 & 1.9 & 7.4 & [14] \\
\hline $\begin{array}{l}\text { Nanoelectrode carbon fibers/manganese(III)- } \\
\text { [2]paracyclophenylporphyrin }\end{array}$ & -0.35 & 1 & 50 & - & [15] \\
\hline $\begin{array}{l}\text { Microelectrode Pt/MnTPAc (manganese } \\
\text { tetraaminophthalocyanine) }\end{array}$ & -0.45 & 14.6 & 5000 & 10.2 & [12] \\
\hline Electrode SPCE/2,6-dihydroxynaphthalene & 0.15 & 4.12 & 200 & $9-12$ & [16] \\
\hline Electrode SPCE/cobalt phthalocyanine & 0.1 & 10.84 & 400 & 9 & this work \\
\hline
\end{tabular}


The sensitivity of chemically modified electrodes is greatly improved using a flow analysis system (FIA) compared to batch [18]. FIA is easier to use in comparison with batch; it increases the reproducibility and simplifies quantification. In addition, the optimization of a method is more rapid, and testing electrodes is more efficient [10]. Understanding the mechanism of reaction is very important, and FIA provides several advantages in electrochemistry that could be useful for this purpose. For example, by using microreactors, one can narrow the diffusion layers of the electrodes that could also "overlap", which helps to optimize the reaction conditions and facilitates the determination of the mechanism. Channon et al. achieved pharmaceutical detection limits with an FIA electrochemical method for hydrazine detection [19]. They described that convective mass transport enhances the electrochemical signal by comparison with diffusive stationary experiments (batch). Recently, nanomolar levels were achieved for the detection of acetaminophen and codeine, using an FIA system combined with multiple pulse amperometry, and the analytes were also quantified in urine and human serum with excellent recoveries [20].

Herein, we describe the electrochemical reduction of peroxynitrite at $0.1 \mathrm{~V}$, using a commercial cobalt (II) phthalocyanine complex ( $\mathrm{CoPc}$ ) and screen-printed carbon electrodes (SPCE). This electrochemical sensor is able to select between the most important interfering species of peroxynitrite (nitrite, nitrate, and hydrogen peroxide) and other molecules (e.g., ascorbic acid and dopamine), due to a specific, but simple design, combined with the advantages of a micro-fluidic system.

In the last part, we show that our proposed method could be used to further study the decay kinetics of PON in the absence and presence of myoglobin. Our method is both a detection and quantification method and a further tool for kinetic studies, as the RSDs values between the classical static UV-Vis method and our method are low (less than 10\%).

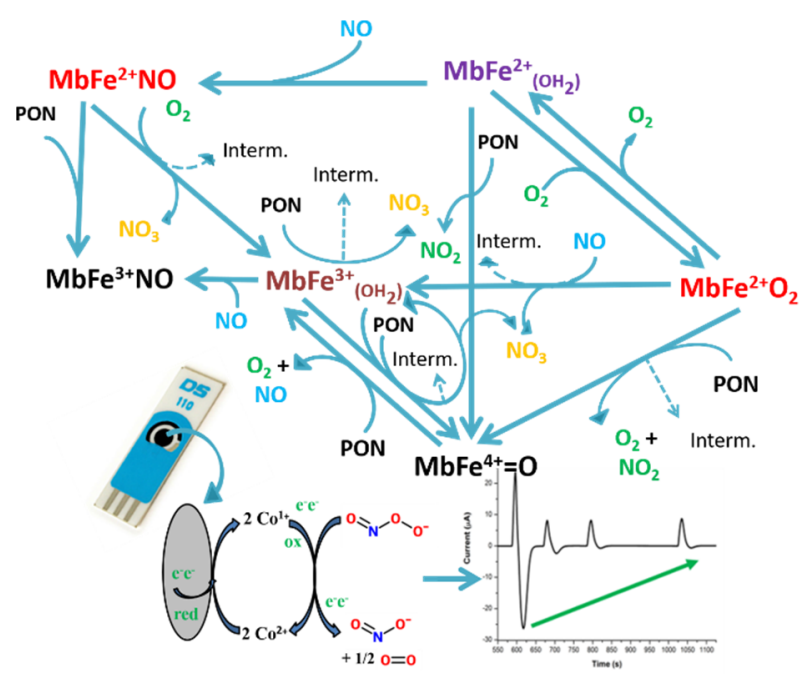

Figure 1. Graphical abstract. ferrylmyoglobin: $\mathrm{MbFe}^{4+}=\mathrm{O}$, oxymyoglobin: $\mathrm{MbFe}^{2+} \mathrm{O}_{2}$, deoxymyoglobin: $\mathrm{MbFe}^{2+}\left(\mathrm{OH}_{2}\right)$, metmyoglobin: $\mathrm{MbFe}^{3+}\left(\mathrm{OH}_{2}\right)$, nitrosylmetmyoglobin: $\mathrm{MbFe}^{3+} \mathrm{NO}$, nitrosylmyoglobin: $\mathrm{MbFe}^{2+} \mathrm{NO}$. This is a schematic representation of the chemical reactions of different forms of myoglobin with peroxynitrite and other interfering species/decomposition products. This scheme is not exhaustive and was inspired from data from different literature references [2,21-26].

\section{Materials and Methods}

Sodium nitrite, hydrogen peroxide $(30 \%)$, manganese dioxide $\left(\mathrm{MnO}_{2}\right)$, myoglobin from equine skeletal muscle, sodium hydroxide $(\mathrm{NaOH})$, sodium phosphate dibasic dihydrate $\left(\mathrm{Na}_{2} \mathrm{HPO}_{4} 2 \mathrm{H}_{2} \mathrm{O}\right)$, cobalt (II) phthalocyanine (CoPc), phthalocyanine $\left(\mathrm{H}_{2} \mathrm{Pc}\right)$, DMF (dimethylformamide), and $\mathrm{TBATBF}_{4}$ (tetrabutylammonium tetrafluoroborate $99 \%$ ), hydrochloric acid $(\mathrm{HCl})$, hydrogen peroxide $30 \%\left(\mathrm{H}_{2} \mathrm{O}_{2}\right)$, sodium nitrite $\left(\mathrm{NaNO}_{2}\right)$, sodium nitrate $\left(\mathrm{NaNO}_{3}\right)$, 
ascorbic acid, and dopamine were acquired from Sigma-Aldrich. Screen-printed carbon electrodes were acquired from DropSens, Spain.

\subsection{Peroxynitrite Synthesis}

Peroxynitrite (PON) was synthesized following a slightly modified procedure [27]. Briefly, a solution of $0.7 \mathrm{M} \mathrm{HCl}+0.6 \mathrm{M} \mathrm{H}_{2} \mathrm{O}_{2}$ was added over an ice-cooled stirring solution of $0.6 \mathrm{M} \mathrm{NaNO}_{2}$, and almost simultaneously, a solution of $3 \mathrm{M} \mathrm{NaOH}$ was added over the mixture to quench the decomposition of peroxynitrite (a yellow solution). After several reaction minutes, a few grams of $\mathrm{MnO}_{2}(0.1 \mathrm{~g} / \mathrm{mL})$ were added to the mixture, to catalyze the decomposition of hydrogen peroxide. After the gas liberation was finished (approximatively $15 \mathrm{~min}$ ), the $\mathrm{MnO}_{2}$ was filtered under vacuum, and the solution was divided into small aliquots $(1 \mathrm{~mL})$ and stored in the freezer $\left(-20^{\circ} \mathrm{C}\right)$.

\subsection{Electrode Chemical Modification}

The SPCE electrodes were modified by drop casting $2 \mu \mathrm{L}$ of a (cobalt phthalocyanine) CoPc solution ( $1 \mathrm{mg} / \mathrm{mL}$ in DMF). The CoPc solution was prepared by dissolving CoPc in DMF $(1 \mathrm{mg} / \mathrm{mL})$, using ultrasonication over $1 \mathrm{~h}$ (power $100 \%$, frequency $37 \mathrm{~Hz}$ ). After the drop-cast, the electrodes were dried at $60{ }^{\circ} \mathrm{C}$ in the oven (for $15 \mathrm{~min}$ ). Before different dropcasting steps, the electrodes were rinsed with DMF and dried with nitrogen. The process was repeated 3 times, without rinsing. The electrode was stabilized by cycling between -0.6 and $0.6 \mathrm{~V}$ (in PBS $\mathrm{pH} 12$ ). Two reduction pre-treatments were proposed for the optimization of the SPCE/CoPc for PON detection: amperometry at $-0.3 \mathrm{~V}$ for different time periods and chemical reduction with $25 \mathrm{mM}$ sodium borohydride, during $20 \mathrm{~min}$, followed by rinsing with deionized water.

\subsection{Meat Extracts and Myoglobin Solutions}

Manz meat (veal under the age of 2) was achieved from a local store. Yellow filtering paper (Filtrak n. 389), ROTI ${ }^{\circledR}$ Spin MINI-3 25 units CL12.1 (gel ultrafiltration, 1.5 Eppendorf tubes, for $3 \mathrm{kDa}$ ), and Sephadex G-25 in PD-10 Desalting Columns were used to remove the strong reducer (sodium borohydride) from the metmyoglobin (metMb) reduced system $(\mathrm{redMb})$. The separation systems were bought from Sigma Aldrich. For oxymyoglobin (redMb) synthesis, a solution of $75 \mathrm{mM}$ of sodium borohydride $\left(\mathrm{NaBH}_{4}\right)$ in $\mathrm{PBS} \mathrm{pH} 9$ was added to a solution of $25 \mu \mathrm{M}$ metMb.

The meat extraction was done according to the procedure from [28]. Briefly, $200 \mathrm{~g}$ of meat were cut in small pieces and blended with $100 \mathrm{~mL}$ of PBS $\mathrm{pH}$ 9. In addition, to the mixture, $400 \mathrm{~mL}$ of $0.1 \mathrm{M}$ PBS ( $\mathrm{pH}$ 9) were added, and the solution was stirred during $30 \mathrm{~min}$, on an ice bath. After stirring, the mixtures were centrifuged $20 \mathrm{~min}$, at $15^{\circ} \mathrm{C}$, at 9000 RPM, and the supernatant was centrifuged in the same conditions. Filtration on yellow filter paper was performed under vacuum and the $\mathrm{pH}$ was adjusted to 9 , using sodium hydroxide. The desired $\mathrm{pH}$ values of the solutions were 12,9 , and 7.4, and the concentration of the phosphate was $100 \mathrm{mM}$.

For PBS pH 9, $\mathrm{Na}_{2} \mathrm{HPO}_{4} \cdot 2 \mathrm{H}_{2} \mathrm{O}(0.1 \mathrm{M})$ and $\mathrm{KCl}(0.1 \mathrm{M})$ were dissolved in $500 \mathrm{~mL}$ of ultra-pure water. The solution of $\mathrm{pH} 12$ was prepared in the same way, but $\mathrm{NaOH}$ was added: $450 \mathrm{~mL}$ solution was titrated with $\mathrm{NaOH}$ (approximately $35 \mathrm{~mL}$ of $1.4 \mathrm{M} \mathrm{NaOH}$ ) until pH 12 and brought to $500 \mathrm{~mL}$ at the end. For PBS, pH 7.4 prepared tablets were used. As we designed the synthesis of PON to obtain high-concentration stock solutions and only added very small amounts of alkaline PON solutions to PBS pH 9 buffer, the $\mathrm{pH} 9$ was practically constant [29].

\subsection{Electrochemistry}

A single-line flow system was coupled with potentiostat using a flow cell provided by DropSens, for the SPCE electrodes (DRP110). The Electrochemical Flow Injection Analysis system (FIA-EC) used is composed of a four-channel Peristaltic Pump-MINIPULS ${ }^{\circledR} 3$ (Gilson, Villiers-le-Bel, France), Injection Valve 77521 Rheodyne (with a $100 \mu \mathrm{L}$ sample 
loop), Flow Cell from DropSens (model DRP-FLWCL), and Potentiostat (Autolab PGSTAT 101). A boxed connector for screen-printed electrodes from Dropsens was used to connect the SPCEs. Each measurement was performed in triplicate.

\subsection{Determination of Apparent Rate Constants and Half-Lives}

The kinetics of PON decay and the scavenging effect of myoglobin on peroxynitrite at $\mathrm{pH} 9$ were assessed using the calculation of half-lives and apparent rate constants of peroxynitrite decay. The static method was used for the measurements of concentrations over time, as pH 9 offers the possibility of having slower decays and changes dynamics toward specific chemical decay reactions. The terms "peroxynitrite" and "PON" are widely accepted for a mixture of $\mathrm{ONOO}^{-}$and $\mathrm{ONOOH}$, depending on the $\mathrm{pH}$. At $\mathrm{pH}$, $\mathrm{ONOO}^{-}$ is assumed to be in excess over the protonated form ONOOH, based on the pKa of PON 6.8. The term "peroxynitrate" refers to a mixture of $\mathrm{O}_{2} \mathrm{NOO}^{-}$and $\mathrm{O}_{2} \mathrm{NOOH}$, depending on the $\mathrm{pH}$. Trivial names: $\mathrm{ONOO}^{-}$, peroxynitrite; $\mathrm{ONOOH}$, peroxynitrous acid; $\mathrm{O}_{2} \mathrm{NOO}^{-}$, peroxynitrate; $\mathrm{O}_{2} \mathrm{NOOH}$, peroxynitric acid.

For the determination of the kinetic parameters, we took in consideration the previously proposed model by which the bimolecular decomposition of $\mathrm{PON}$ is dominant at $\mathrm{pH}$ 9 , according to the following reaction $[30,31]$ :

$$
\mathrm{HOONO}+\mathrm{ONOO}^{-}->2 \mathrm{NO}_{2}^{-}+\mathrm{O}_{2}+\mathrm{H}^{+}+2 \mathrm{e}^{-}
$$

According to this model, the rate law should follow pseudo first-order kinetics at $\mathrm{pH}$ 9, due to the excess of $\mathrm{ONOO}^{-}$. Our aim was to validate the FIA-EC method as a tool for the determination of rate order and kinetic parameters by comparing the results with the classical UV-Vis method. In this particular case, the first purpose was to establish by both UV-Vis and FIA methods if the reaction follows indeed pseudo first-order kinetics or second/higher-order kinetics at $\mathrm{pH} 9$.

Two approaches were used for the confirmation of rate order and the calculation of apparent rate constants and half-lives: the first method (namely called from now on "Method $\mathrm{A}^{\prime}$ ) uses the plotting of all the integrated rate law data, according to the assumed rate order. Briefly, this was done as follows: the linearity (from the value of $\mathrm{R}^{2}$ ) of the graphs $\ln$ (concentration) (for (pseudo) first-order) or 1/concentration (for second-order) vs. time and the correlation of the observed half-life (extrapolation from the graph $\mathrm{t}_{1 / 2 \mathrm{obs}}$ ) with the calculated half-life $\left(t_{1 / 2 c a l c}\right)$. The half-lives for (pseudo) first-order and secondorder reactions were calculated with the following formulas, respectively: $\ln 2 / \mathrm{k}$ and $1 / \mathrm{k} \cdot \mathrm{C}_{0 \mathrm{PON}} \cdot \mathrm{C}_{0 \mathrm{PON}}$ is the initial concentration of PON and $\mathrm{k}$ is the (apparent) rate constant. For the linearity, we considered the $\mathrm{R}^{2}$ values. If $\mathrm{R}^{2}$ approaches 1 , is significantly higher than the $R^{2}$ of the other model, and there is good similarity between $t_{1 / 2 \text { calc }}$ and $t_{1 / 2 \text { obs }}$, the corresponding apparent order of the reaction is attributed to the detriment of the other apparent order. Each decay rate constant determination was plotted for a total of $180 \mathrm{~s}$.

The second method (namely called from now on "Method B") was the "half-life method" described by Ira Levine, in the "Physical Chemistry" book, chapter 16, "Reaction kinetics" [32]. This method can be applied when the rate law has the form $r=k[A]^{n}$. Based on Equation (1) and considering the excess of $\mathrm{ONOO}^{-}$, this method would follow the equation $\mathrm{r}=\mathrm{k}[\mathrm{ONOOH}]^{\mathrm{n}}$, therefore determining the rate order in $\mathrm{ONOOH}$. According to this method adapted to our particular case, one first plots the concentration vs. time and then should be able to fit the equation with a single-exponential decay function if $n=1$ (based on Equation (2), where parameter $\mathrm{k}$ (the apparent pseudo first-order rate constant in our case, $\mathrm{k}_{\mathrm{obs}}$ ) is solved after compilation. Secondly, one performs the extrapolation of $t_{1 / 2}$ for various concentrations and then plots the $\log t_{1 / 2}$ vs. $\log C_{0}$ [32]. The slope of the logarithmic graph (that should have a linear fit) will establish the order of the reaction in reactant $\mathrm{A}, n$, where $n=1-$ slope. The two methods, $\mathrm{A}$ and $\mathrm{B}$, were compared at the end.

$$
\mathrm{C}_{\mathrm{PON}}=\mathrm{C}_{0 \mathrm{PON}} \times \mathrm{e}^{-\mathrm{kt}}
$$


where $\mathrm{C}_{\mathrm{PON}}$ is the PON concentration at a specific moment in time.

Both A and B kinetic methods were used for the UV-Vis method and for our proposed FIA-EC method. The molar extinction coefficient of $1670 \mathrm{M}^{-1} \mathrm{~cm}^{-1}$ was used to calculate the concentration of $\mathrm{ONOO}^{-}$at $302 \mathrm{~nm}[33,34]$.

\subsection{Surface Characterization}

Fourier transform infrared (FTIR) spectra were recorded using a ThermoScientific FTIR instrument (Nicolet 8700, Pleasantville, NY, USA) equipped with a VariGATR accessory (Harrick Scientific Products, Inc., New York, NY, USA). KBr pellets were used as reference, and the powders were ground with $\mathrm{KBr}$ to create a solid pellet. For the ATR measurement technique, the Perkin Elmer GX FTIR spectrometer equipped with a Pike MIRacle having a $1.8 \mathrm{~mm}$ round diamond crystal was used. Diamond has an intrinsic absorption from approximately 2300 to $1800 \mathrm{~cm}^{-1}$, which limits is usefulness in this region.

Micro-Raman spectroscopy measurements were performed on a Horiba Jobin Yvon LabRam HRMicro-Raman system combined with a $473 \mathrm{~nm}$ laser diode as an excitation source. Visible light was focused using a $100 \times$ objective. The scattered light was collected by the same objective in backscattering configuration, dispersed by an $1800 \mathrm{~mm}$ focal length monochromator, and detected using a CCD.

SEM images were obtained using an electron microscope FEI-QUANTA 200 equipped with wolfram filament (W), at the ICECHIM laboratory (Bucharest, Romania). The SEM images were taken at an accelerating voltage of $25-30 \mathrm{kV}$ using a gaseous secondary electron detector (GSED).

Absorption spectra were recorded using Ocean Optics UV-VIS-NIR spectrometer, in the 200-1100 nm range.

The Limit of Detection and the Limit of Quantification were calculated with the following formulas: $\mathrm{LOD}=3 \sigma_{\mathrm{b}} / \mathrm{m}$, and $\mathrm{LOQ}=10 \sigma_{\mathrm{b}} / \mathrm{m}$, in which $\sigma_{\mathrm{b}}$ represents the standard deviation of the background and $\mathrm{m}$ is the slope of the calibration graph. The sensitivity of the sensor was calculated from the slope of the calibration curve (plot concentration vs. current).

\section{Results and Discussion}

Detecting reactive oxygen and nitrogen species is of great importance for many domains. Peroxynitrite, despite being a short half-life oxidative species, induces powerful oxidative stress effects on cells. Scavengers are important tools to eliminate this oxidative stress. Myoglobin is one of the scavengers [35], as it is an oxygen-binding protein from the heme group. Cobalt phthalocyanine was already used in the literature as a bio-mimetic material for biosensors [36]. It has a similar scavenging role when it comes to PON. As the metal cobalt center of the heme, similar to iron, has multiple oxidation states, the reduction of PON seems to be catalyzed by CoPc through redox reactions. We demonstrate here that the $\mathrm{Co}^{2+} / \mathrm{Co}^{1+}$ redox couple is more effective than the high potential electrochemical methods reported in the literature for the electrochemical detection of PON, as it offers better selectivity. Cyclic voltammetry as well as other techniques (linear sweep voltammetry or differential pulse voltammetry) were used to determine that this redox reaction of $\mathrm{PON}$ is apparently an irreversible process.

Before presenting and discussing the results, several other important factors regarding PON are to be mentioned, which are factors that are also important challenges to overcome in developing a selective and sensitive sensor for PON for meat extracts. (i) PON is most stable in cold alkaline solutions, without any metals and carbonyl compounds [30] and even so, it slowly decomposes, mainly, to nitrite. (ii) Below $\mathrm{pH} 12$, the decomposition rate increases, and at $\mathrm{pH} 7$, the half-life of $\mathrm{PON}$ is below $1 \mathrm{~s}$. (iii) Acidic $\mathrm{pH}$ favors the decomposition to nitrate. (iv) Temperature, buffers, or several scavengers (e.g., myoglobin in meat as in Figure 1) influence the stability of PON [30,31]. Proteins tend to precipitate at $\mathrm{pH}$ values around 12 , so such alkaline environment is not suitable for our purpose. As the decay of $\mathrm{PON}$ is slower at $\mathrm{pH} 9$ than at neutral $\mathrm{pH}$ values, $\mathrm{pH} 9$ is an optimal compromise 
for the detection of PON. At this $\mathrm{pH}$ value, the decay to nitrite is the predominant pathway, and it depends on peroxynitrite concentration. Due to these factors, we needed a fast response technique to help us distinguish between PON, nitrite, and nitrate, and to combat batch problems (mixing of the aliquots added for detection would increase the noise of the measurement, the concentration of the analyte will not be homogenous, etc.).

\subsection{Batch Determination of Peroxynitrite Using SPCE/CoPc Electrodes}

\subsubsection{Characterization of the Deposited CoPc Films on the SPCE}

SEM analysis of the morphology revealed that in accordance with the literature, the CoPc molecules tend to form random agglomerates [37] of various sizes (between 0.4 and $10 \mu \mathrm{m}$ in length and a few hundred $\mathrm{nm}$ in thickness and width) depending on the surface used for the deposition (Figure 2a,b). The thin films were obtained by drop casting $\mathrm{CoPc}$, due to $\pi$ stacking (as the macrocycle has 18 delocalized $\pi$ electrons), similar to other materials, such as graphene. This method is deposition is cost-effective and rapid.

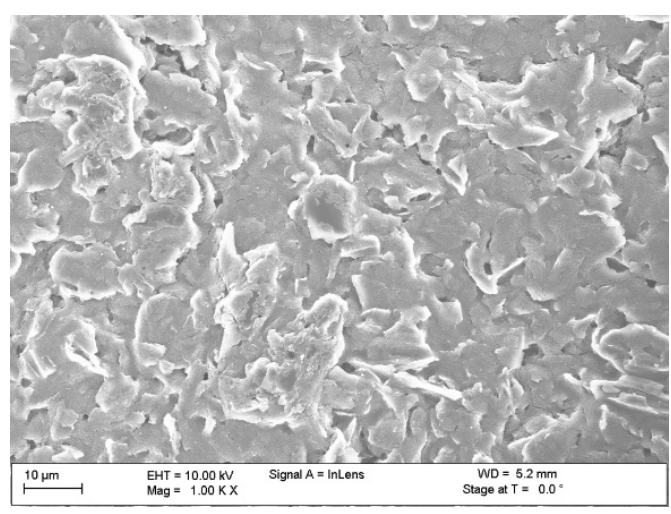

(a)

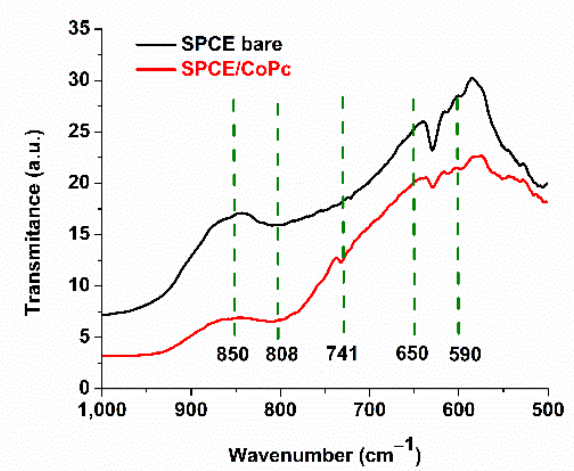

(c)

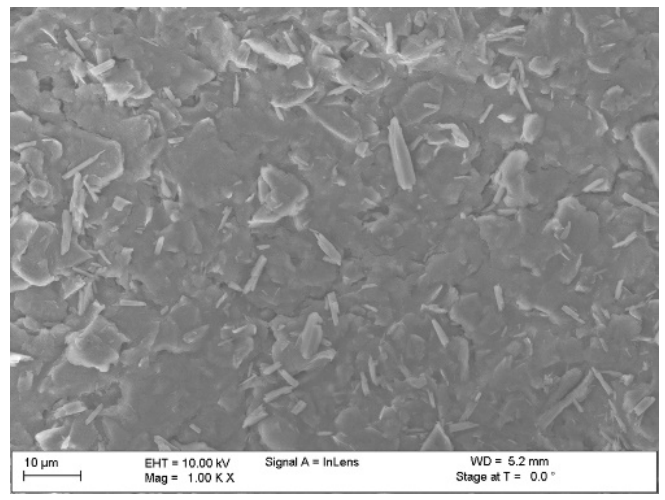

(b)

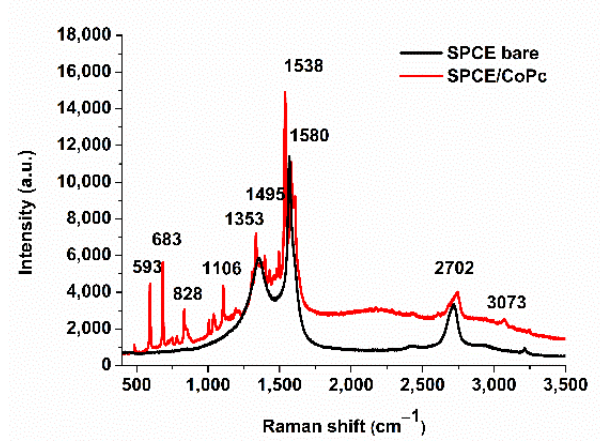

(d)

Figure 2. SEM characterization of the (a) unmodified SPCE and (b) SPCE/CoPc, (c) FTIR spectra of unmodified SPCE and modified SPCE with CoPc (SPCE/CoPc) [1], (d) Raman spectra of unmodified and CoPc modified SPCE.

The FTIR analysis (Figure 2c) proves the presence of CoPc on the surface of the electrode, especially due to the $741 \mathrm{~cm}^{-1}$ band in the fingerprint region, corresponding to phthalocyanine in plane vibrations [38]. Other vibrations belonging to the graphitic structure of SPCE are also observed: deformation of C-C out of aromatic plane $\left(650 \mathrm{~cm}^{-1}\right)$, vibrations of $\mathrm{C}-\mathrm{H}$ in the aromatic plane $\left(850\right.$ and $\left.808 \mathrm{~cm}^{-1}\right)$.

In the Raman spectrum of CoPc (Figure 2d), there are active modes of the symmetry $\mathrm{A} 1 \mathrm{~g}$ at $592 \mathrm{~cm}^{-1}$ (benzene radial), $834 \mathrm{~cm}^{-1}$, B1g at $684 \mathrm{~cm}^{-1}$ (macro breathing and benzene radial), $1542 \mathrm{~cm}^{-1}$ ( $\mathrm{C}=\mathrm{N}$ stretching mode), and $\mathrm{B} 2 \mathrm{~g}$ at $1498 \mathrm{~cm}^{-1}$ (pyrrole stretch) $[39,40]$. The HUMO-LUMO gap energy of CoPc is $1.9 \mathrm{eV}$. 
After the morphological characterization of the surface of the electrode, we also used electrochemistry to extensively characterize the electrode. Cyclic voltammetry gave rise to two anodic and two cathodic peaks (corresponding to $\mathrm{Co}^{3+} / \mathrm{Co}^{2+}$ and $\mathrm{Co}^{2+} / \mathrm{Co}^{1+}$ redox processes), as previously reported [11]. In this paper, we targeted the exploitation of the $\mathrm{Co}^{2+} / \mathrm{Co}^{1+}$ redox couple (Figure $3 \mathrm{a}$ ), due to the occurrence at more negative potentials $\left(\mathrm{E}_{0} \approx 0.1 \mathrm{~V}\right)$, than the couple $\mathrm{Co}^{3+} / \mathrm{Co}^{2+}\left(\mathrm{E}_{0} \approx 0.65 \mathrm{~V}\right)$, and because, besides good sensitivity, there is the possibility to reach a remarkable selectivity for peroxynitrite. It can be observed that upon several scans (five cycles), the electrode reaches a steady state. Similar peaks were observed in the literature [41].

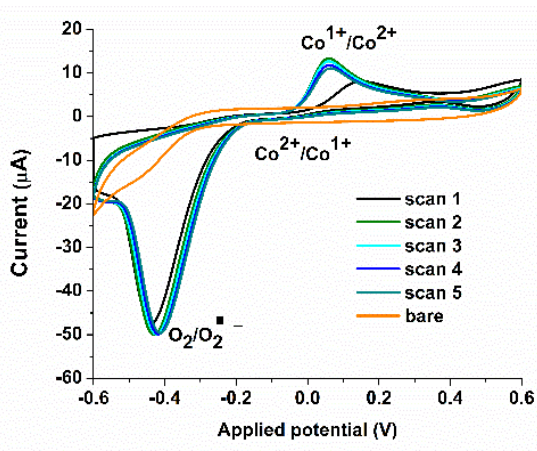

(a)

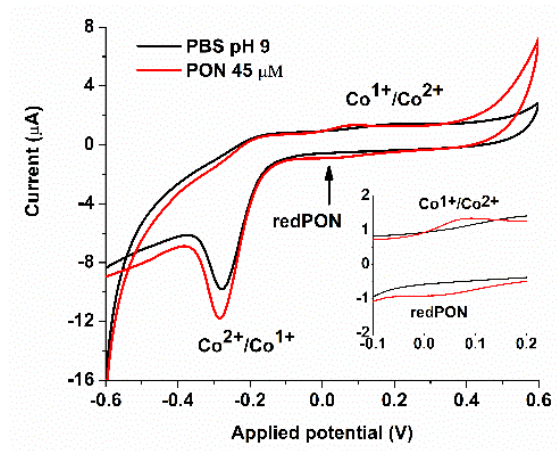

(b)

Figure 3. Cyclic Voltammetry (CV) of (a) the screen-printed carbon electrode (SPCE)/ cobalt phthalocyanine $(\mathrm{CoPc})$ electrode upon different scans, in PBS pH 12 [1]. The oxido-reduction processes are presented for the cobalt metallic center. (b) Cyclic voltammetry was registered using the SPCE/CoPc electrode in the absence (black) and in the presence (red) of $45 \mu \mathrm{M}$ PON (scan rate $9 \mathrm{mV} / \mathrm{s}$ ), PBS $\mathrm{pH}$ 9. Zoom in of the redox peaks for PON from the same plot.

Cyclic voltammetry $(\mathrm{CV})$, in the -0.6 to $0.6 \mathrm{~V}$ range, was used to determine the redox process of $\mathrm{PON}$, using the SPCE/CoPc electrode, at $\mathrm{pH} 9$ and $\mathrm{pH}$ 12. A higher $\mathrm{pH}$ value (12) presented enhanced anodic and cathodic peaks of the biosensor (Figure 3a) than a lower $\mathrm{pH}$ value ( $\mathrm{pH}$ 9, Figure $3 \mathrm{~b}$, both in the presence and absence of $\mathrm{PON}$ ), but high alkalinity interferes with the integrity of proteins (the final goal of our work) and may interfere with the integrity of the film, so it was not used further for analytical purposes, only for biosensor characterization. The redox process involving peroxynitrite at $\mathrm{pH} 9$ takes place at around $0.1 \mathrm{~V}$, with $\mathrm{Ec}=0.047$ and $\mathrm{Ea}=0.072\left(\Delta \mathrm{E}=25 \mathrm{mV}=\mathrm{E}_{\text {cathode }}-\mathrm{E}_{\text {anode }}\right)$, but there is a small current in the reduction, suggesting that the oxidation might be irreversible. The calculated formal potential (the redox standard potential, $\mathrm{E}^{0}$ ) is $0.06 \mathrm{~V}$ vs. $\mathrm{Ag} / \mathrm{AgCl}$ pseudoreference electrode. Following the Nernst equation (Equation (3), where $\mathrm{a}_{\text {red }}$ represents the concentration of reduced species and $\mathrm{a}_{\mathrm{ox}}$ represents the concentration of oxidized species, [32]) described below, we can conclude that two electrons are involved in the redox process (transferred in the cell reaction) at $25^{\circ} \mathrm{C}$. This conclusion is consistent with the nature of the peroxynitrite oxidant (usually described as a two-electron oxidant).

$$
\mathrm{E}_{\text {cell }}=\mathrm{E}_{\text {cathode }}-\mathrm{E}_{\text {anode }}=\mathrm{E}^{0}+0.059 / \mathrm{n} \cdot \lg \mathrm{a}_{\text {red }} / \mathrm{a}_{\mathrm{ox}}
$$

Furthermore, under another probable mechanism, an irreversible reduction takes place around $-0.3 \mathrm{~V}$, probably involving also the chemical oxidative reaction of peroxynitrite over the metallic center: cobalt being chemically oxidized by PON, which is electro-reduced, with a higher current, depending on the concentration of PON (Figure 3b).

If the anodic/cathodic current is proportional to the scan rate, the process is an adsorption-controlled process, and if the plot I vs. $v^{1 / 2}$ is linear, the redox processes are more likely diffusion-controlled ones [42]. For this purpose, cyclic voltammetry was used to determine the correlation between the cathodic current and the scan rate for scan rates in the range of $16-800 \mathrm{mV} / \mathrm{s}$ (Figure $4 \mathrm{a}$ ). At lower scan rates, a linear correlation was 
obtained only for the square root of the scan rate, suggesting a diffusion-controlled process. Deviation from linearity usually means that other processes are involved, processes related to the surface, such as adsorption, ligand-species interaction, etc. At higher scan rates (above $256 \mathrm{mV} / \mathrm{s}$ ), the correlation between Ipc vs $v^{1 / 2}$ is not linear anymore, suggesting more a mixture of surface and diffusion-controlled processes (Figure $4 \mathrm{~b}$ ).

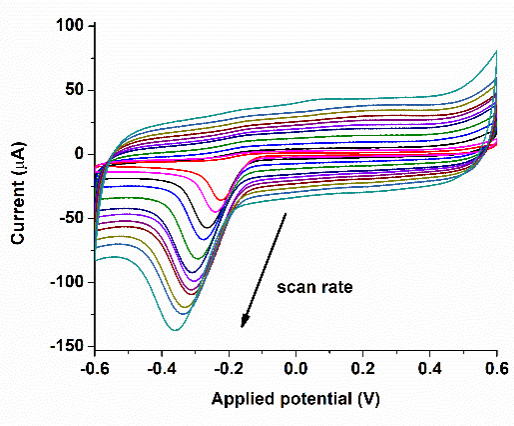

(a)

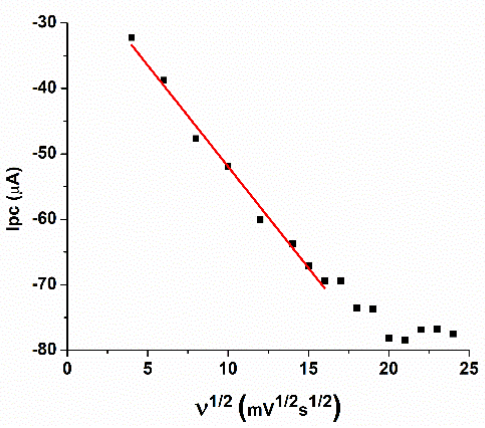

(b)

Figure 4. (a) Cyclic voltammetry of the SPCE/CoPc electrode for $50 \mu \mathrm{M}$ PON, PBS pH 12. (b) The dependence of the cathodic current (around $-0.3 \mathrm{~V}$ ) with the square root of the scan rate.

The SPCE is a three-electrode electrochemical system. The screen-printed area of the carbon-based working electrode (WE, black circle) of the SPCE is $0.126 \mathrm{~cm}^{2}$, which is surrounded by the $\mathrm{Ag} / \mathrm{AgCl}$ pseudoreference electrode (silver) and counter/auxiliary electrode (CE, black). The chemical modification should not cover the $\mathrm{CE}$ and the reference electrode, but the surface coverage should be optimal. Starting from a solution of classical concentration for CoPc $(1 \mathrm{mg} / \mathrm{mL})$, we drop-casted 1 and $2 \mu \mathrm{L}$ of the solution on the electrodes and calibrated them by DPV, from -0.4 to $0.3 \mathrm{~V}$, step potential $5 \mathrm{mV}$, amplitude $25 \mathrm{mV}$, modulation time $50 \mathrm{~ms}$, scan rate $10 \mathrm{mV} / \mathrm{s}$ (Figure $5 \mathrm{a}$ ). The sensitivity for the $2 \mu \mathrm{L}$ drop-casted CoPc was $0.083 \mathrm{nA} \mu \mathrm{M}^{-1}$, in comparison to $0.057 \mathrm{nA} \mu \mathrm{M}^{-1}$ for the $1 \mu \mathrm{L}$ drop-casted CoPc. More than $2 \mu \mathrm{L}$ is difficult to deposit without covering the other electrodes. These sensitivities are very low, but further optimization helps us improve them, especially using chronoamperometry at the optimized potential. The efficiency of different cobalt phthalocyanine layers was studied using Cyclic Voltammetry measurements. By drop-casting different layers of solution of $\mathrm{CoPc}$, the best sensitivity for PON was achieved for three layers (drop-casting $2 \mu \mathrm{L}$ in three successive steps, that also included

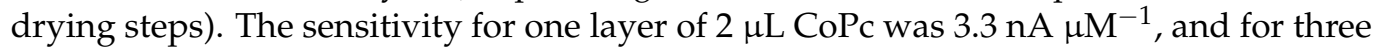

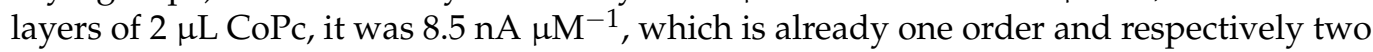
orders of magnitude improvements from the DPV method, but the LODs remained almost the same ( $5.45 \mu \mathrm{M}$ and $5.14 \mu \mathrm{M}$, respectively).

Chronoamperometry was used to study the preliminary potential for an improved quantitative detection of PON. Two different potentials were used, and both worked on the catalyt-

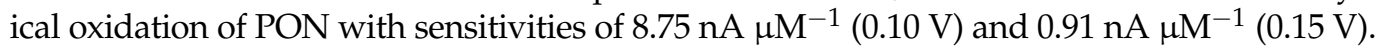

Based on the data described above, we propose a simplified mechanism of the catalytic process, involving two electrons as calculated from Nernst equation:

$$
\mathrm{Co}{ }^{\mathrm{II}} \mathrm{PC}+\mathrm{e}^{-} \rightarrow \mathrm{Co}^{\mathrm{I}} \mathrm{PC}
$$

(reduction)

$$
2 \mathrm{Co}^{\mathrm{I}} \mathrm{PC}+\mathrm{ON}^{\mathrm{V}} \mathrm{OO}^{-} \rightarrow \text { intermediary complex } \rightarrow 2 \mathrm{Co}^{\mathrm{II}} \mathrm{PC}+\mathrm{N}^{\mathrm{III}} \mathrm{O}_{2}{ }^{-}+\frac{1}{2} \mathrm{O}_{2}+2 \mathrm{e}^{-}
$$




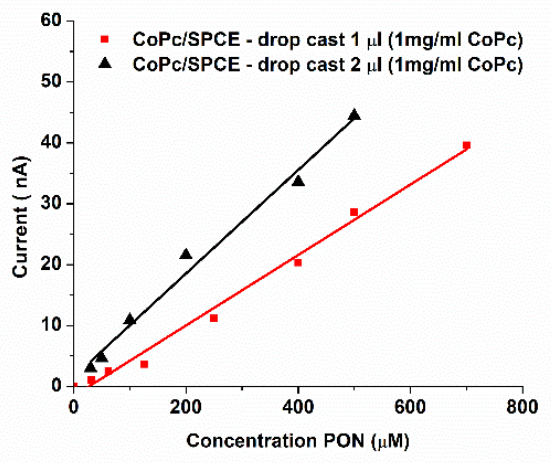

(a)

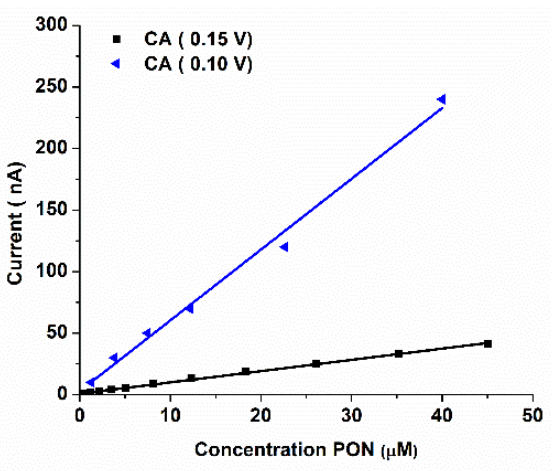

(b)

Figure 5. (a) Calibration curves for $1 \mu \mathrm{L}$ and $2 \mu \mathrm{L}$ drop-casted CoPc solution ( $1 \mathrm{mg} / \mathrm{mL}$ in DMF) on the SPCE (from DPV measurements) (b) Calibration curves from the amperometric response at $+0.15 \mathrm{~V}$ (black) and $+0.10 \mathrm{~V}$ (blue), using a GCE/CoPc electrode.

(oxidation/reduction)

In order to prove that the proposed mechanism involves the catalytic site of the metal phthalocyanine, we compared our electrochemical signals with the metal-free phthalocyanine (the exclusion of the catalytic site). Experiments were performed with $\mathrm{H}_{2} \mathrm{Pc}$ (dihydrogen phthalocyanine), which is the phthalocyanine ring without any metal coordinated to the nitrogen ligands. The $\mathrm{H}_{2} \mathrm{Pc}$ was not responsive to peroxynitrite, underlining the importance of the metallic center in this catalytic process (data not shown).

The surface coverage was calculated using the equation Equation (6):

$$
\Gamma=\mathrm{Q} / \mathrm{nFA}
$$

where $\Gamma$ is the coverage of CoPC immobilized upon the desired electrode surface $\left(\mathrm{mol} \mathrm{cm}^{-2}\right)$, $\mathrm{Q}$ is the charge taken from the integration of the oxidation wave resulting from the $\mathrm{Co}^{1+} /{ }^{2+}$ couple recorded in a $\mathrm{pH} 7.4$ phosphate buffer solution (PBS) at slow scan rates, $\mathrm{n}$ is the number of electrons taking place in the electrochemical process, F is the Faraday constant, and $\mathrm{A}$ is the geometrical electrode area (without recourse to any surface roughness corrections, and it was calculated to be $0.126 \mathrm{~cm}^{-2}$, as the diameter of the WE is $4 \mathrm{~mm}$ ) [43]. Using this calculation method, there was a surface coverage of $7.0558 \times 10^{-9} \mathrm{~mol} \mathrm{~cm}^{-2}$ for the drop-casted CoPC SPEs, while the commercial (DRP 410, Drop Sense electrode) had a similar surface coverage $\left(8.9643 \times 10^{-9} \mathrm{~mol} \mathrm{~cm}^{-2}\right)$. These kinds of commercial electrodes are recommended for the detection of hydrogen peroxide at low potentials $(0.4 \mathrm{~V})$.

\subsubsection{Batch Optimization of the CoPc-Modified Electrodes for PON Detection}

Bedoui et al. [44] mention that species such as ascorbic acid, nitrite and nitrate, uric acid, hydrogen peroxide, and others could interfere in blood or other biological samples with the signal that one may obtain for peroxynitrite. For this purpose, we studied a series of interfering species using Cyclic Voltammetry and a GCE-modified CoPc and compared the signal with the ones for PON at the same concentration, $100 \mu \mathrm{M}$ (Figure 6). The biological concentrations of these interfering species are low, but we used the same concentration as for PON measurements, which usually is produced at a rate of up to 50-100 $\mu \mathrm{M} / \mathrm{min}$, but the steady-state reaction is in the nanomolar range, for hours [45]. Ascorbic acid gave rise to an oxidation peak around $0.4 \mathrm{~V}$, hydrogen peroxide around $0.6 \mathrm{~V}$, and PON was electro-catalyzed around $0.1 \mathrm{~V}$ (as already described above). Nitrate is not electrochemically active, and nitrite was not responsive within the chosen potential windows, meaning that using potentials around $0.1 \mathrm{~V}$ gives a very good selectivity toward PON. 


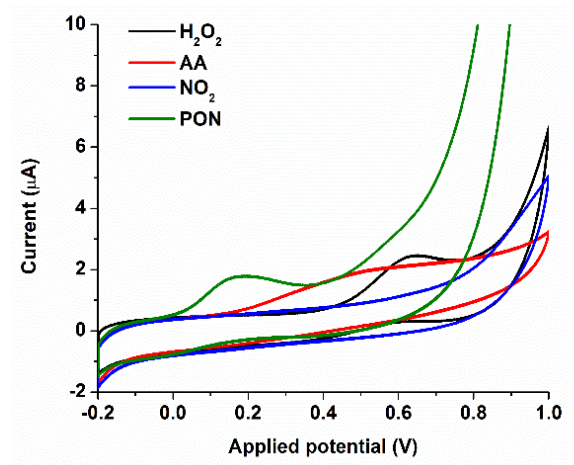

Figure 6. Evaluation of the interfering species using $\mathrm{CV}$ for $100 \mu \mathrm{M}$ peroxynitrite (PON-green): $100 \mu \mathrm{M}$ ascorbic acid (AA-red), $100 \mu \mathrm{M}$ hydrogen peroxide $\left(\mathrm{H}_{2} \mathrm{O}_{2}\right.$-black), $100 \mu \mathrm{M}$ nitrite $\left(\mathrm{NO}_{2}\right.$ - blue), using a glassy carbon electrode (GCE)/CoPc electrode. Scan rate $100 \mathrm{mV} / \mathrm{s}$, electrolyte: PBS pH $90.1 \mathrm{M}+0.1 \mathrm{M} \mathrm{KCl}[1]$.

More sensitive techniques than CV (Cyclic Voltammetry) such as LSV (Linear Sweep Voltammetry) and DPV (Differential Pulse Voltammetry) were used for further characterization of the electrodes. LSV voltammograms (Figure 7a) in the potential window of -0.4 to $0.3 \mathrm{~V}$ were used to observe the electro-oxidation of PON over the SPCE/CoPc electrode at different PON concentrations. The oxidation potential shifts from $0.075 \mathrm{~V}$ (for $72 \mu \mathrm{M}$ PON) to higher potentials (around $0.1 \mathrm{~V}$ for $145 \mu \mathrm{M}$ PON).

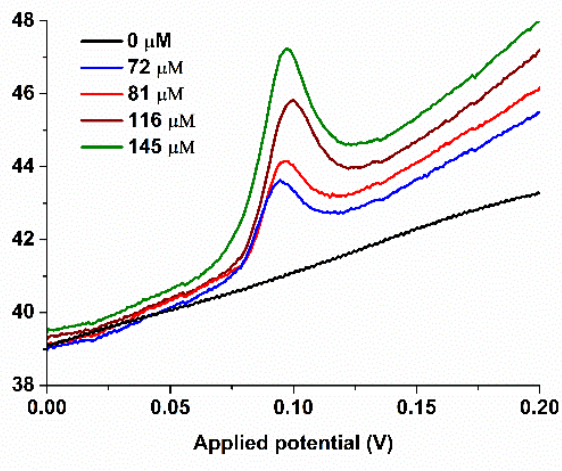

(a)

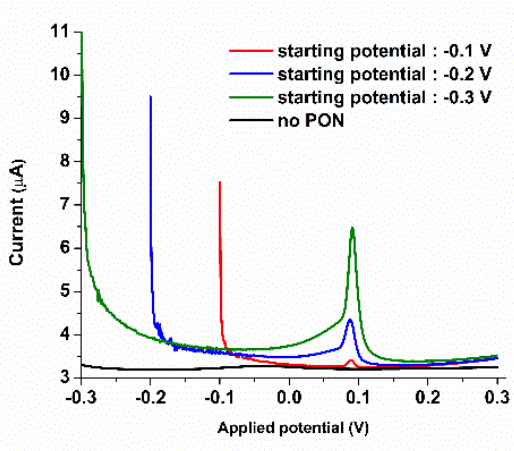

(b)

Figure 7. (a) LSV using SPCE/CoPc for the detection of PON, using droplets of analyte over the electrode, -0.4 to $0.3 \mathrm{~V}$ (electrolyte: PBS pH $90.1 \mathrm{M}+0.1 \mathrm{M} \mathrm{KCl}$ ), using different PON concentrations. (b) DPV of the SPCE/CoPc in the presence (red, blue, green) and absence (black) of $125 \mu \mathrm{M}$ of PON, using different negative starting potentials $(-0.1 \mathrm{~V},-0.2 \mathrm{~V}$, and $-0.3 \mathrm{~V})$.

Differential Pulse Voltammetry (DPV) revealed that upon reduction of the CoPc films by starting the scans from lower potentials, the cumulative current (both cathodic and anodic) increases (Figure 7b). This suggests that the pre-treatment of the electrode could improve the response of the electrode for PON because of the reduction of $\mathrm{Co}^{2+}$ to $\mathrm{Co}^{1+}$. In addition, the shape of the DPV peak suggests that, besides diffusion, other processes occur (e.g., adsorption of product or reactant molecules on the surface of the electrode or even the coordination of the $\mathrm{ONOO}^{-}$molecule to the metallic catalytic center).

\subsection{FIA Optimization of the SPCE/CoPc Electrodes for PON Detection}

Initially, we did hypothesize that while the oxidation of $\mathrm{Co}^{1+}$ to $\mathrm{Co}^{2+}$ takes place, it can also be part of the redox process involving the reduction of peroxynitrite to nitrite. Starting from this hypothesis, an important issue was understanding how to overcome the apparent irreversible oxidation of PON from batch electrochemical analysis. The ability of flow injection analysis in understanding reaction mechanisms and complicated electrode 
kinetics [46] served as an important tool to select between the oxidation potential of peroxynitrite and of other species, such as hydrogen peroxide, and the electrocatalytic reduction potential of peroxynitrite was unraveled and exploited.

FIA coupled with chronoamperometry gave us the opportunity to develop a very selective sensor for PON, using the gathered information from the batch electrochemistry. First, we wanted to establish the optimal potential, so we used chronoamperometry and changed the applied potentials $(0.00,0.10$, and $0.25 \mathrm{~V})$ on a SPCE/CoPc electrode. This study helped us to determine that the reduction of PON occurs below $0.1 \mathrm{~V}$, as opposed to the oxidation of PON that occurs above $0.1 \mathrm{~V}$ (Figure 8a). Due to the several other advantages already described, a single line flow injection system was employed for further experiments using the revealed reduction potential for further optimization of the PON sensor.

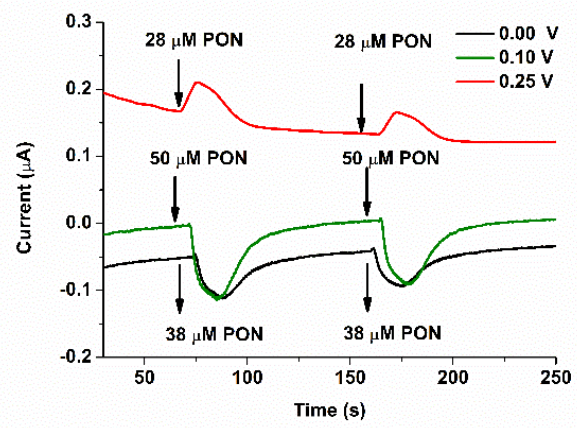

(a)

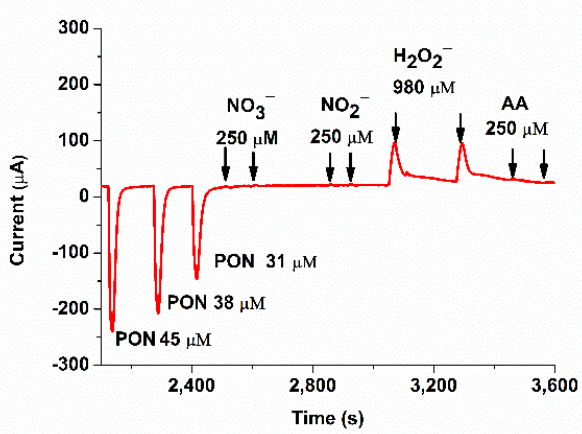

(b)

Figure 8. (a) Chronoamperometry (CA) spectra of the flow injection analysis (FIA) using different potentials: $0.00 \mathrm{~V}$ (black), $0.10 \mathrm{~V}$ (green), and $0.25 \mathrm{~V}$ (red) [1]. (b) Interfering species study using the FIA equipment and chronoamperometry at $0.1 \mathrm{~V}$, in $\mathrm{PBS} \mathrm{pH}$ 9: $250 \mu \mathrm{M}$ nitrate, $250 \mu \mathrm{M}$ nitrite, hydrogen peroxide $980 \mu \mathrm{M}$ and $250 \mu \mathrm{M}$ ascorbic acid (AA), as compared to 31, 38, and $45 \mu \mathrm{M}$ PON signals.

Determination of the optimum flow rate was done using injections of $200 \mu \mathrm{M}$ of PON (PBS pH 12) and amperometry at $0.1 \mathrm{~V}$. The curve flow rate vs. current was fitted with $\mathrm{R}^{2}=0.9195$ with a fourth-grade polynomial function. The optimal flow rate of $0.4 \mathrm{~mL} / \mathrm{min}$ and a voltage of $0.1 \mathrm{~V}$ were used to further optimize the detection process, as the response time of this flow rate is fast, around $10 \mathrm{~s}$. Interfering species were also evaluated using chronoamperometry at 20-fold higher concentration than $\mathrm{PON}$ for $\mathrm{H}_{2} \mathrm{O}_{2}$ and 5-fold higher concentration for the other species. As determined also by batch Cyclic Voltammetry, hydrogen peroxide gave rise to oxidation signals, but with very low sensitivity (Figure $8 b$ ) in contrast to PON, which gave rise to sensitive reduction signals. SPCE/CoPc electrodes are known to be used for the oxidation of hydrogen peroxide at $0.4 \mathrm{~V}$.

As we have already shown for in batch electrochemistry (Figure 8b), the pre-treatment of electrodes with a reduction potential might be very important before the quantification of PON. We optimized the amount of time needed to reduce the CoPc film to obtain the best CA signal for PON. We used FIA amperometry for different time periods, 0, 20, 30, 60, 120, and $180 \mathrm{~s}$ and the reducing potential $-0.3 \mathrm{~V}$, which is the redox potential for $\mathrm{Co}^{2+} / \mathrm{Co}^{1+}$. We determined that applying a potential of $-0.3 \mathrm{~V}$ for $60 \mathrm{~s}$ was the optimal procedure (data not shown).

We have performed the calibration (Figure 9a) using the flow injection system, at $0.1 \mathrm{~V}$ with the chronoamperometric method (Figure 9b), and we obtained a sensitivity of $6.31 \mathrm{nA}$ $\mu \mathrm{M}^{-1}\left(\mathrm{R}^{2}=0.9938\right)$, after the pre-treatment at $-0.3 \mathrm{~V}$ for $60 \mathrm{~s}$. The calculated LOQ $=2.41$ $\mu \mathrm{M}$, the calculated LOD $=0.72 \mu \mathrm{M}$, and the linear range is 3-180 $\mu \mathrm{M}$. The reproducibility varied from $95 \%$ to $99 \%$ ( $50 \mu \mathrm{M}$ PON) and the RSD for each calibration concentration (in triplicates) did not exceed $10 \%$. The analytical parameters are very good if we consider several facts: (i) our unstable oxidative anion species are hard to detect, and (ii) screen-printed carbon electrodes are disposable electrodes. 


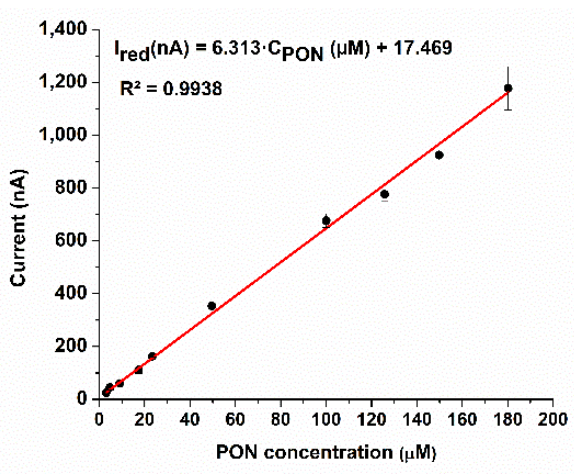

(a)

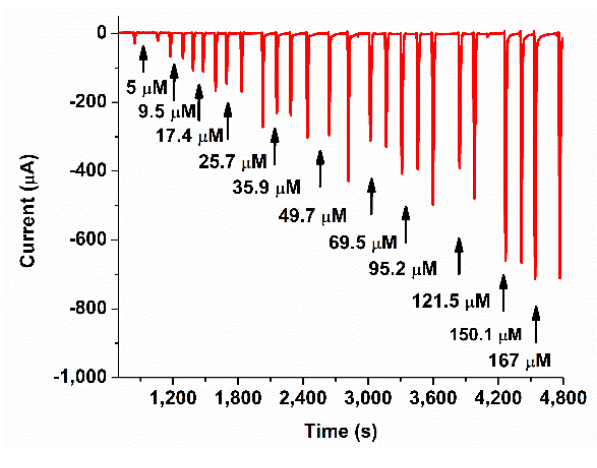

(b)

Figure 9. (a) Calibration curve of the SPCE/CoPc electrode for PON, PBS pH 9. (b) Chronoamperogram measured using the FIA system and the SPCE $/$ CoPc electrode, $\mathrm{E}=0.1 \mathrm{~V}$, flow rate $=0.4 \mathrm{~mL} / \mathrm{min}$ [1].

By replacing the electrochemical polarization of the SPCE/CoPc electrode during the $60 \mathrm{~s}$, at $-0.3 \mathrm{~V}$ with the chemical oxidation of the CoPc film using sodium borohidrate $(25 \mathrm{mM})$, for $20 \mathrm{~min}$, the calibration was improved to Ired $(\mathrm{nA})=10.843 \cdot \mathrm{C}_{\mathrm{PON}}(\mu \mathrm{M})-36.484$ $\left(\mathrm{R}^{2}=0.9925\right)$. The new LOD was equal to $0.42 \mu \mathrm{M}$, and the LOQ was $1.4 \mu \mathrm{M}$.

The LODs of our method reached nanomolar level, the same level of PON under physiological conditions. Even though we did not study the interaction of PON in the absence or in the presence of myoglobin at physiological $\mathrm{pH}$, our method has physiological relevance because it could be further used for this purpose by miniaturization of the electrodes with the same electrocatalytic bio-mimetic film. The micro-dimension of the surface-active area of the electrode offers enough sensitivity to study, for example, the formation of PON by cells (the cells being also in the micrometer range) involved in the oxidative burst (micromolar range of PON), in the redox signaling, or even in the steady state of PON (nanomolar range), as the literature suggests [47,48].

\subsection{UV-Vis and Determination of Synthesized PON for Kinetic Studies}

Molina et al. [30] describe the influence of buffer and $\mathrm{pH}$ over the stability of peroxynitrite solutions ("peroxynitrite" being the term widely accepted for peroxynitrite and peroxynitrate). The rate constants depend on $\mathrm{pH}$, ionic strength, temperature, scavengers, and other parameters. Several mechanisms of PON decay have been already proposed in the literature. In acidic conditions, the isomerization of peroxynitrite occurs (mainly present as $\mathrm{ONOOH}$, the form that decays rapidly to nitrate), independent of total peroxynitrite concentration. If $\mathrm{pH}$ is $\geq 7$, nitrite is the main decomposition product of PON (the higher the $\mathrm{pH}$ value and concentration of $\mathrm{PON}$, the higher the conversion yield to nitrite) [31]. As mentioned in Section 2.5, the Equation (1) describing the bimolecular decomposition of PON (as opposite to the mononuclear isomerization, as termed by IUPAC) is supposed to be predominant at $\mathrm{pH}=9$, especially when $\mathrm{PON}$ concentration is higher than $0.1 \mathrm{mM}[32,49]$.

The reaction from Equation (1) was proposed to follow second-order or pseudo firstorder kinetics, depending on $\mathrm{pH}$ [31].

Molina et al. [30] proposed that the decomposition of PON to nitrite has more intermediate steps than the one in Equation (1) (disproportionation reaction followed by the formation of intermediary/adduct species and then followed by decomposition to nitrite). The formation of the adduct is very rapid in the range of $10^{4} \mathrm{M}^{-1}$ at alkaline $\mathrm{pH}$. The last direct decomposition step to nitrite is much slower than the other elementary steps [31]. So, this could be the rate-determining step in these series of proposed reactions involved. In addition, the disproportionation of $\mathrm{PON}$ at $\mathrm{pH} 9$ seems to favor the equilibrium toward $\mathrm{ONOO}^{-}$, as knowing the $\mathrm{pKa}$ of $\mathrm{ONOOH}$ (6.8), one can calculate the concentration of $\mathrm{ONOOH}$ at $\mathrm{pH}$ 9. For a concentration of $150 \mu \mathrm{M} \mathrm{ONOO}^{-}$in $\mathrm{PBS}^{2} \mathrm{pH} 9$, there are only $0.946 \mu \mathrm{M} \mathrm{ONOOH}$, and for $50 \mu \mathrm{M} \mathrm{ONOO}^{-}$in PBS pH 9, there are $0.3154 \mu \mathrm{M}$ 
ONOOH. At $\mathrm{pH} 9$, one can say that $\mathrm{ONOOH}$ concentration is insignificant (less than $1 \%$ of the $\mathrm{ONOO}^{-}$concentration) if $\mathrm{pKa} 6.8$ is taken in consideration. Nevertheless, the pKa of $\mathrm{ONOOH}$ depends on the ionic strength and $\mathrm{pH}$, so these calculated values could be further refined [49].

If $\mathrm{ONOOH}$ is present in small amounts at $\mathrm{pH}$ 9, one can assume that the isomerization is insignificant (as the only form to isomerize is $\mathrm{ONOOH}$ ) and $\mathrm{PON}$ decay should follow the pseudo first-order reaction at this $\mathrm{pH}$.

Although the mechanism of PON decay is not fully understood, we took in consideration the generally agreed model depicted in Equation (1) for $\mathrm{pH} 9$, as the aim was to determine the accuracy of the FIA-EC method compared to the classical UV-Vis one in determining the kinetic parameters. We checked both possibilities of reaction order for Equation (1), i.e., the pseudo first-order and the second-order.

We calculated the decay (apparent) rate constant and half-lives of PON using two methods: Method A involves the assumption that both (the (pseudo) first and second order) integrated rate laws could be possible. One finds the rate constant value from the slope of the two graphs: $\ln \left(C_{P O N}\right)$ vs. time, where $\mathrm{t}_{1 / 2}=\ln 2 / \mathrm{k}$ (for the (pseudo) first-order reaction) and $1 / C_{P O N}$ vs. time, where $t_{1 / 2}=1 /\left(C_{0 P O N} \cdot k\right)$ (for the second-order reaction). Using the slope of the most linear plot, one calculates the corresponding half-time.

The second method, Method B, also named the "half-life method", is based on the several half-time values from the concentration vs. time plot of the data, and it plots them after as $\log \left(t_{1 / 2}\right)$ vs. $\log \left(C_{P O N}\right)$, where $n=1$-slope ( $n$ being the (apparent) rate order). This method is more precise, as it is difficult to assess the linearity of a plot (as in Method A).

The idea was to compare the UV-Vis results with our proposed FIA-EC method using SPCE/CoPc electrodes. The UV-Vis spectrum of synthesized genuine PON is less complicated than other synthetic methods (such as using the nitric oxide and superoxide donor-based synthesis, SIN-1). The molar extinction coefficient of $1670 \mathrm{M}^{-1} \mathrm{~cm}^{-1}$ can be used to calculate the concentration of genuine $\mathrm{ONOO}^{-}$at $302 \mathrm{~nm}$ (Figure 10a) [33]. We evaluated the stability of our synthesized PON solution using UV-Vis spectrometry. As we have already described [1], because we performed our measurements at alkaline $\mathrm{pH}$ values, we had a significant amount of nitrite in the genuine PON solutions. The amount of nitrite is correlated with the absorbance at $355 \mathrm{~nm}$. Calibration was performed at this wavelength using a Griess reagent-based protocol, $\left(y=0.0488 \cdot C_{\mathrm{NO} 2}(\mu \mathrm{M})+0.0076\right.$, $\mathrm{R}^{2}=0.9971$, data not shown), the amount of nitrite was also assessed to be $72 \pm 5 \mathrm{mM}$ for a $117 \mathrm{mM}$ PON solution (improved PON synthesis), at $\mathrm{pH}$ 9, in PBS 0.1 M. This amount of nitrite is confirmed in the literature [24]. Nitrite reaches a plateau between $\mathrm{pH} 9$ and 10 [50].

The kinetic plots at $302 \mathrm{~nm}$ (concentration vs. time, Figure 10b for UV-Vis data and Figure 10d for FIA-EC data) were fitted with a single exponential curve in Origin 8.5 software, as suggested in the literature $[2,24,30,34,51]$. The $\log \left(t_{1 / 2}\right)$ vs. $\log \left(C_{P O N}\right)$ was plotted, and the slope was equal to slope $=1-n$, where $n$ is the reaction order (Figure 10c,e). As it can be observed, Method B can be applied for both UV-Vis, as well as for the FIA-EC described in Section 3.2, and it will be further descried and compared with Method A (Figure 10f). 
Table 2. Calculated pseudo first-order decay rates constants for PON, in PBS pH $9(0.1 \mathrm{M})$, at $25^{\circ} \mathrm{C}$, determined using classical UV-Vis method at $302 \mathrm{~nm}$ and the FIA-EC method, using the SPCE/CoPc (Method A).

\begin{tabular}{|c|c|c|c|c|}
\hline Pseudo First-Order Decay Rates & \multicolumn{4}{|c|}{$k\left(s^{-1}\right)$} \\
\hline Method & \multirow{2}{*}{ SPCE/CoPc } & \multirow{2}{*}{$\mathbf{R}^{2}$} & \multirow{2}{*}{ UV-Vis } & \multirow{2}{*}{$\mathbf{R}^{2}$} \\
\hline Samples & & & & \\
\hline PON $50 \mu \mathrm{M}$ & $0.0084 \pm 0.0011$ & 0.9830 & $0.0089 \pm 0.0010$ & 0.9985 \\
\hline PON $150 \mu \mathrm{M}$ & $0.0028 \pm 0.0012$ & 0.9975 & $0.0025 \pm 0.0004$ & 0.9877 \\
\hline $\mathrm{Mb} 15 \mu \mathrm{M}+\mathrm{PON} 50 \mu \mathrm{M}$ & $0.0134 \pm 0.0010$ & 0.9815 & Not possible & - \\
\hline $\mathrm{Mb} 15 \mu \mathrm{M}+\mathrm{PON} 150 \mu \mathrm{M}$ & $0.0086 \pm 0.0020$ & 0.9842 & Not possible & - \\
\hline Meat diluted $10+$ PON $50 \mu \mathrm{M}$ & $0.0200 \pm 0.0048$ & 0.9020 & Not possible & - \\
\hline
\end{tabular}

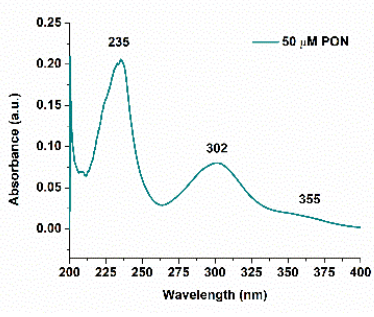

(a)

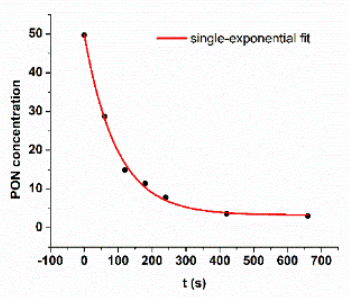

(d)

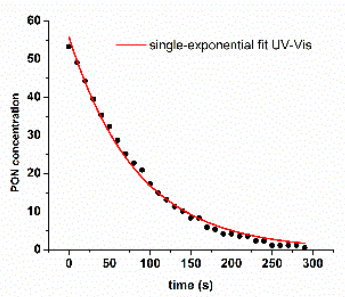

(b)

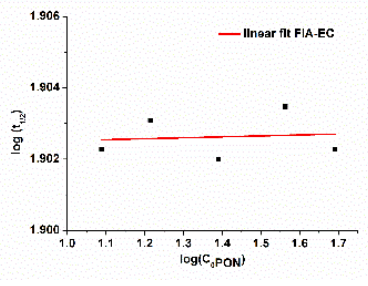

(e)

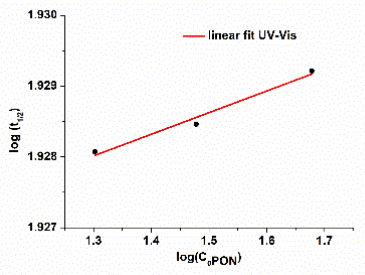

(c)

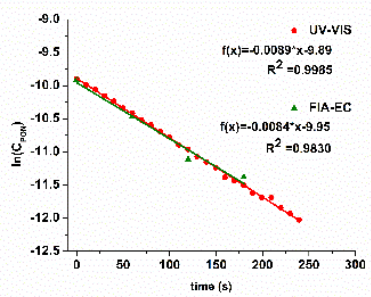

(f)

Figure 10. (a) UV-Vis spectra of $50 \mu \mathrm{M}$ PON, pH 9, PBS $0.1 \mathrm{M}$. The illustration of the second method "half-lives method": plot of $C_{P O N}$ vs. time, fitted with a single-exponential equation $\left(\mathrm{y}=\mathrm{y}_{0} \cdot \mathrm{e}^{-\mathrm{kx}}\right)$ for the data obtained using (b) the UV-Vis method and (d) our proposed FIA-EC method. Plot of $\log \left(C_{O P O N}\right)$ vs. $\log \left(t_{1 / 2}\right)$ from (c) UV-Vis and from (e) FIA-EC, fitted linearly for the determination of apparent reaction order from the slope of the equation (Method B). The illustration of the first method (Method A): (f) plot of $\ln \left(C_{P O N}\right)$ vs. time according to pseudo first order, fitted linearly for both UV-Vis and our proposed FIA-EC method (linear correlation function, $\mathrm{R}^{2}$ linear correlation coefficient and apparent kinetic constant is determined from these plots, data presented in Table 2). All spectra represent the data for $50 \mu \mathrm{M}$ PON, pH 9, PBS $0.1 \mathrm{M}$.

\subsection{UV-Vis Determination of Different Forms of Myoglobin}

In meat extracts, different oxidation forms of myoglobin are present, as we depicted in Figure 1. The conversion of reduced myoglobin $\left(\mathrm{MbFe}^{2+} \mathrm{OH}_{2}\right.$ or $\left.\mathrm{MbFe}^{2+} \mathrm{O}_{2}\right)$ to metmyoglobin $\left(\mathrm{MbFe}^{3+}\left(\mathrm{OH}_{2}\right)\right)$ can be followed using UV-Vis due to PON scavenging activity (Figure 11): the concentration of the redMb solutions can be verified by measuring the absorbance at 417,542 , and/or $580 \mathrm{~nm}\left(\varepsilon_{417}=128 \mathrm{mM}^{-1} \mathrm{~cm}^{-1}, \varepsilon_{542}=13.9 \mathrm{mM}^{-1}\right.$ $\mathrm{cm}^{-1}$, and $\varepsilon_{580}=14.4 \mathrm{mM}^{-1} \mathrm{~cm}^{-1}$ ) [21], and the spectrum of metMb has a maximum of absorbance at $502\left[\varepsilon_{502}=10.2 \mathrm{mM}^{-1} \mathrm{~cm}^{-1}\right]$ and $610 \mathrm{~nm}$ at $\mathrm{pH} 6.4$, and the Soret band absorbance maximum is at $408 \mathrm{nM}$ at $\mathrm{pH} 7.4$ [52]. So, the scavenging effect could be identified using UV-Vis, but no quantification of PON decay can be done in a direct, rapid, sensitive, and selective manner. 


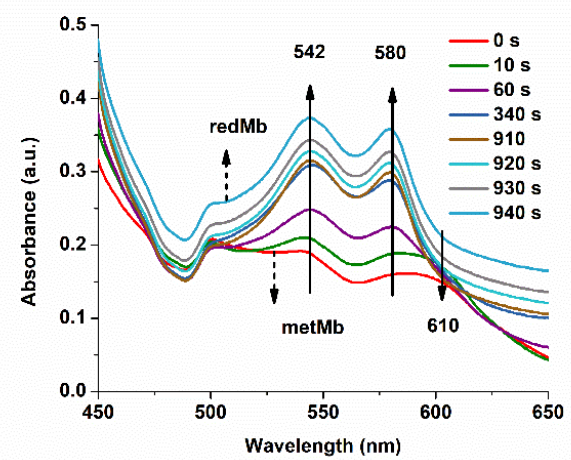

(a)

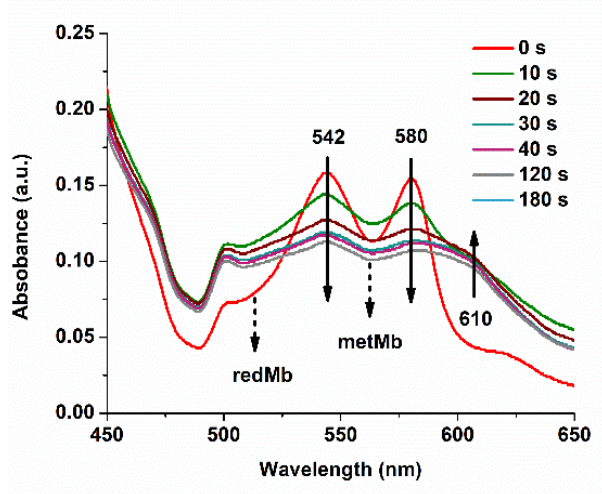

(b)

Figure 11. (a) UV-Vis spectra for different reaction times of $75 \mathrm{mM} \mathrm{NaBH}_{4}$ and $25 \mu \mathrm{M}$ metMb (PBS $\mathrm{pH}$ 9). (b) UV-Vis spectra for different incubation times $(0,10,20,30,40,120$, and $180 \mathrm{~s})$ of $100 \mu \mathrm{M}$ $\mathrm{PON}$ with $10 \mu \mathrm{M}$ redMb (PBS $\mathrm{pH}$ 9).

The quantification of the concentration of redMb was realized with measurements at $580 \mathrm{~nm}$. The concentration of the stock meat extract was determined to be $480 \mu \mathrm{M}$, which corresponds to ca. $20 \mathrm{mg}$ of myoglobin for $1 \mathrm{~g}$ of meat. Moreover, if we use the absorption at $525 \mathrm{~nm}$ (representing the isosbestic point for the absorption in visible range for the 3 forms of myoglobin) and a molar extinction coefficient of $7.6 \mathrm{mM}^{-1} \mathrm{~cm}^{-1}$, we obtained a value of $485 \mu \mathrm{M}$ of myoglobin for the same stock solution. A more complex method for determining the content of myoglobin was described by Krzywicki, and improved by Tang, in 2004 [53].

The reactions of PON with myoglobin or meat were studied both with the electrochemical and spectrophotometric methods. Figure 12 describes the evolution of the $\mathrm{Mb}$ absorption peaks during $\mathrm{Mb}$ incubation with 50 and $150 \mu \mathrm{M}$ PON. For PON $50 \mu \mathrm{M}$, almost no change was observed after 11 min of incubation, but the same incubation of metMb with $150 \mu \mathrm{M}$ PON induced a more significant change, with decrease in absorbance at 542 and $580 \mathrm{~nm}$, and the appearance of a band at $700 \mathrm{~nm}$, corresponding to a qualitative evaluation of the catalytic reaction. The same incubation was studied with our FIA-EC method, also to obtain quantitative information regarding the catalyzed PON decay.

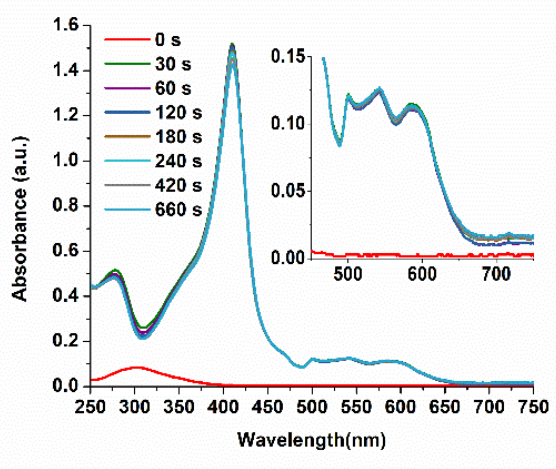

(a)

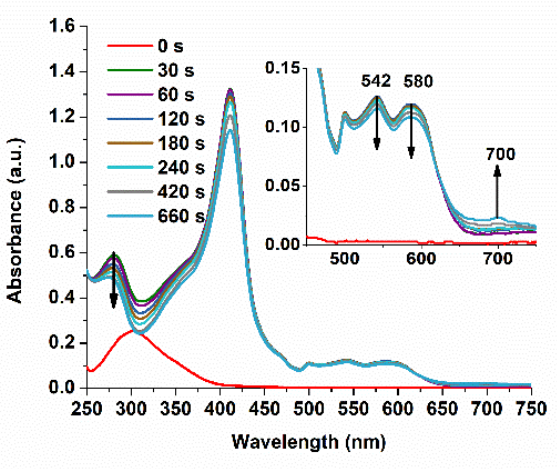

(b)

Figure 12. UV-Vis spectra of (a) $50 \mu \mathrm{M}$ PON and (b) $150 \mu \mathrm{M}$ PON incubated with $15 \mu \mathrm{M}$ metMb, at different incubation periods.

\subsection{Studying the Reaction of Myoglobin with Peroxynitrite with FIA-EC}

The incubated solutions of $50 \mu \mathrm{M}$ and $150 \mu \mathrm{M}$ PON with $15 \mu \mathrm{M}$ Mb were also investigated, in parallel, with our FIA-EC optimized method (Figure 13). It was expected that the kinetics between the two concentrations of PON to be different due to the ratio between $\mathrm{PON}$ and $\mathrm{Mb}$, although the difference could be overcome by the kinetics of spon- 
taneous PON decay independent of $\mathrm{Mb}$, which presents opposite behavior. More precisely, increasing PON concentrations favor pseudo first-order reaction in relation to $\mathrm{Mb}$ and deviation to second-order reaction in the case of spontaneous PON decay. Moreover, approximatively at least eight equivalents of PON are necessary for the complete oxidation of myoglobin (depending on experimental conditions and pseudo first-order kinetics) [21]. The recovered current was converted into PON concentration with the calibration curve, and in the following sections, we discuss and compare the decay of PON using these data.

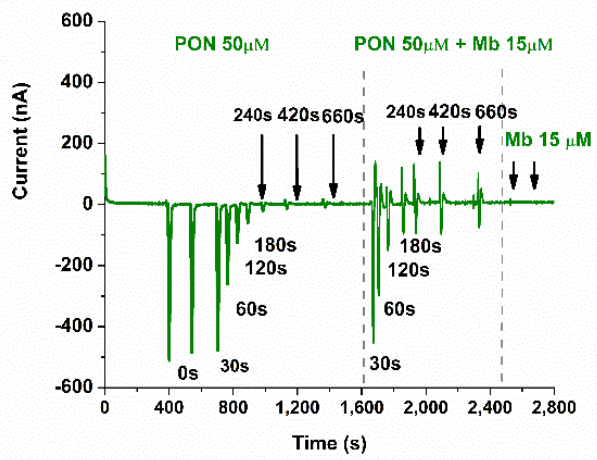

(a)

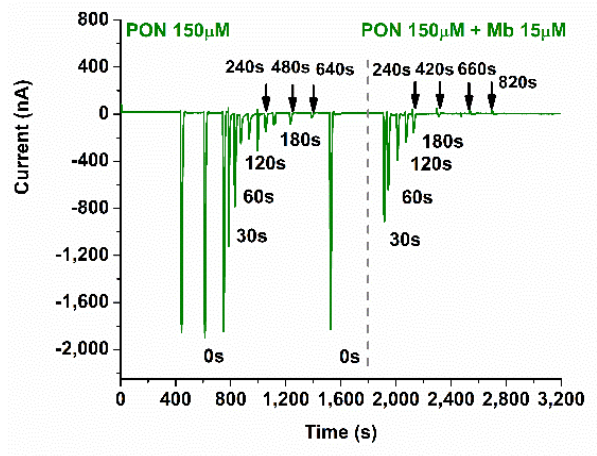

(b)

Figure 13. Chronoamperogram using the FIA-EC system for (a) $50 \mu \mathrm{M}$ and (b) $150 \mu \mathrm{M}$ PON, in the presence and in the absence of $15 \mu \mathrm{M}$ metMb, at different incubation periods $(0,30,60,120,240,420$, $660,820 \mathrm{~s})$. The decomposition of PON alone was studied at the same incubation periods to prove that the recovery of the current is due to the presence of $\mathrm{PON}$ in the metMb solution and not to the metMb itself (PBS pH 9, 0.1M, E $=0.1 \mathrm{~V}$ and flow rate $0.4 \mathrm{~mL} / \mathrm{min}$ ). The values obtained in these studies were further used for kinetic calculations.

\subsection{Studying the Reaction between Myoglobin from Meat Extracts and Peroxynitrite Using FIA-EC}

Meat extracts were first diluted 10-fold and analyzed with UV-Vis to determine the quantity of myoglobin. Using the isosbestic point at $525 \mathrm{~nm}$, as described above, we determined $15 \mu \mathrm{M}$ of myoglobin (independent of the oxidation form, Figure 14a). The incubation of the meat extracts with PON was studied both with UV-Vis and FIA-EC. Using the optimized calibration curve of the electrochemical method, we developed (Ired $\left.(\mathrm{nA})=10.843 \cdot \mathrm{C}_{\mathrm{PON}}(\mu \mathrm{M})-36.484, \mathrm{R}^{2}=0.9925\right)$, quantified PON during its incubation with both $\mathrm{Mb} 15 \mu \mathrm{M}$ and meat extracts diluted 10 times in PBS $\mathrm{pH}$ 9, and compared it to a normal decomposition rate of $\mathrm{PON}$, at $\mathrm{pH}$, without any scavenger (Figure 14b).

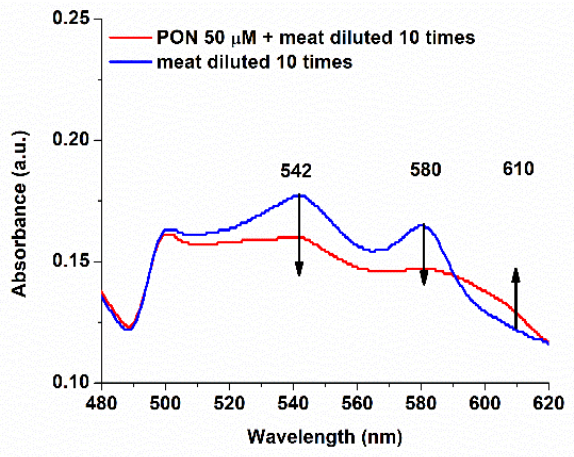

(a)

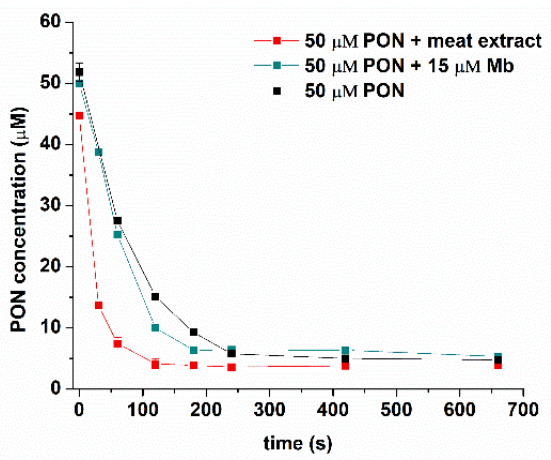

(b)

Figure 14. (a) UV-Vis spectra of meat diluted 10 times in PBS pH 9 in the presence of $50 \mu \mathrm{M}$ PON and in absence, during $12 \mathrm{~min}$. (b) The graphs of concentration (from FIA-EC) over time for $50 \mu \mathrm{M}$ PON decay in the absence (black) or in the presence of $15 \mu \mathrm{M} \mathrm{Mb}$ (cyan) or meat extract (red). 
It can be clearly observed that the decomposition of PON takes place at a faster rate for the PON samples incubated with both $\mathrm{Mb}$ and meat extracts.

Calculated apparent reaction orders, apparent rate constants, and half-lives determined using UV-Vis spectrophotometry and our FIA-EC method are presented in Tables $2-5$ and further discussed in the following two sections. All measurements and calculations were done for PBS $\mathrm{pH} 9,0.1 \mathrm{M}$, at $25^{\circ} \mathrm{C}$.

Table 3. The "half-life" method: Determined values of half-life for PON and calculation of rate orders. PBS pH 9 (0.1 M), at $25^{\circ} \mathrm{C}$, classical UV-Vis method at $302 \mathrm{~nm}$ and the FIA-EC method, using the SPCE/CoPc (Method B).

\begin{tabular}{ccccc}
\hline Half-Lives and Rate Orders & \multicolumn{2}{c}{$\mathbf{t}_{\mathbf{1} / \mathbf{2}} \mathbf{( s )}$} & \multicolumn{3}{c}{ Calculated Values for Rate Order * } \\
\hline & SPCE/CoPc & UV-Vis & SPCE/CoPc & UV-Vis \\
\hline PON $50 \mu \mathrm{M}$ & $81.33 \pm 8.69$ & $84.73 \pm 3.53$ & $1.0000 \pm 0.0014$ & $1.0030 \pm 0.0016$ \\
\hline PON $150 \mu \mathrm{M}$ & $252.12 \pm 2.97$ & $230.75 \pm 5.13$ & $1.0001 \pm 0.0001$ & $1.0054 \pm 0.0009$ \\
\hline $\mathrm{Mb} 15 \mu \mathrm{M}+$ PON $50 \mu \mathrm{M}$ & $64.83 \pm 1.64$ & Not possible & $1.0004 \pm 0.0008$ & Not possible \\
\hline $\mathrm{Mb} 15 \mu \mathrm{M}+\mathrm{PON} 150 \mu \mathrm{M}$ & $88.12 \pm 0.03$ & Not possible & $1.0001 \pm 0.0001$ & Not possible \\
\hline Meat diluted $10+$ PON $50 \mu \mathrm{M}$ & $19.77 \pm 0.10$ & Not possible & $1.9442 \pm 0.0587$ & Not possible \\
\hline
\end{tabular}

${ }^{*}$ Rate order $=\mathrm{n}=1$ - slope of the $\log \left(C_{0}\right)$ vs. $\log \left(t_{1 / 2}\right)$, the data were fitted with a single exponential function based on equation $\mathrm{y}=\mathrm{y}_{0} \cdot \mathrm{e}^{-\mathrm{kx}}$. Estimations of the rate orders were done in the case of values lower than $10^{-4}$.

Table 4. Observed first-order decay rates constants for PON, in PBS pH $9(0.1 \mathrm{M})$, at $25^{\circ} \mathrm{C}$, determined using the classical UV-Vis method at $302 \mathrm{~nm}$ and the FIA-EC method, using the SPCE/CoPc (Method B).

\begin{tabular}{|c|c|c|}
\hline \multirow[t]{2}{*}{ Apparent First-Order Rate Constants } & \multicolumn{2}{|c|}{$k\left(s^{-1}\right)$} \\
\hline & SPCE/CoPc & UV-Vis \\
\hline PON $50 \mu \mathrm{M}$ & $0.00862 \pm 0.0007$ & $0.0080 \pm 0.0018$ \\
\hline PON $150 \mu \mathrm{M}$ & $0.00275 \pm 0.0012$ & $0.0030 \pm 0.0004$ \\
\hline $\mathrm{Mb} 15 \mu \mathrm{M}+\mathrm{PON} 50 \mu \mathrm{M}$ & $0.01690 \pm 0.0010$ & Not possible \\
\hline $\mathrm{Mb} 15 \mu \mathrm{M}+\mathrm{PON} 150 \mu \mathrm{M}$ & $0.00780 \pm 0.0020$ & Not possible \\
\hline
\end{tabular}

Table 5. Calculated second-order decay rates constants for PON, in $\mathrm{PBS} \mathrm{pH} 9(0.1 \mathrm{M})$, at $25{ }^{\circ} \mathrm{C}$, determined using classical UV-Vis method at $302 \mathrm{~nm}$ and the FIA-EC method, using the SPCE/CoPc (Method B).

\begin{tabular}{ccc}
\hline Apparent Second-Order Rate Constants & \multicolumn{2}{c}{$\mathbf{k}\left(\mathbf{M}^{-\mathbf{1}} \mathbf{s}^{-\mathbf{1}}\right)$} \\
\hline SPCE/CoPc & UV-Vis \\
\hline Mb $15 \mu \mathrm{M}+$ PON $50 \mu \mathrm{M}$ & $311.87 \pm 7.9600$ & Not possible \\
\hline Meat diluted 10 + PON $50 \mu \mathrm{M}$ & $891.76 \pm 220.54$ & Not possible \\
\hline
\end{tabular}

3.6.1. Estimation of the Apparent Rate Decay Orders of PON in the Absence and Presence of Myoglobin

Using Method A (Table 2), for $50 \mu \mathrm{M}$ PON, the $\mathrm{R}^{2}$ values for the plot according to a first-order apparent kinetics (0.9985) were higher than for a second-order one (0.9246); as for $150 \mu \mathrm{M}$ PON, the results were not conclusive $(0.9872$ for pseudo first order and 0.9877 for second order). Taking in consideration Equation (1) and the excess of $\mathrm{ONOO}^{-}$ comparing to $\mathrm{ONOOH}$, these results from Method A are relevant and indicate pseudo first-order kinetics.

Using Method B, the apparent decay of PON is also a pseudo first-order reaction for both $50 \mu \mathrm{M}$ and $150 \mu \mathrm{M}$ (see Table 3), with calculated order values of 1.0030 and 1.0054 for the UV-Vis method, in comparison with 1.0000 and 1.0001 for the FIA-EC method. The differences between these two methods were less than 3\% (acceptable error values). 
The fitting curves for both $50 \mu \mathrm{M}$ PON (Chi-Sqr $\left.=3.9770, \mathrm{R}^{2}=0.9865\right)$ and $150 \mu \mathrm{M}$ PON Chi-Sqr $=1.9293, R^{2}=0.9990$ ) were proper, as tolerance criteria were satisfied.

Our results are in accordance with the literature, describing that especially concentrations above $100 \mu \mathrm{M}$ present deviations from (pseudo) first-order reactions as second-order in total peroxynitrite concentration at $\mathrm{pH} 9[30,31]$. These deviations are most pronounced at $\mathrm{pH} 9$ [50].

Method $B$ helped us to assess numerically the reaction order out of our data acquired with the FIA-EC method for the interaction of 50 and $150 \mu \mathrm{M}$ PON with $15 \mu \mathrm{M} \mathrm{Mb}$, and the calculated reaction orders were 1.0222 and 1.0001, suggesting also a pseudo first-order kinetics in both cases. Deviations in apparent second order from the single-exponential curve were higher in the case of $50 \mu \mathrm{M}$ PON $+15 \mu \mathrm{M} \mathrm{Mb}$, as expected (meaning that the model could be adjusted, as pseudo first-order kinetics were not fulfilled for PON:Mb, Chi-Sqr $\left.=15.7763, R^{2}=0.9446\right)$. These deviations were smaller for $150 \mu \mathrm{M}$ PON $+15 \mu \mathrm{M}$ $\mathrm{Mb}$ (Chi-Sqr $\left.=17.9047, \mathrm{R}^{2}=0.9941\right)$, as pseudo first-order kinetics were fulfilled: $\mathrm{PON}: \mathrm{Mb}$ was 10:1.

Using both methods (A and B), the only studied interaction that gave clear secondorder decay for PON was the meat diluted 10 times with $50 \mu \mathrm{M}\left(\mathrm{R}^{2}=0.9020 \mathrm{vs}\right.$. $\mathrm{R}^{2}=0.9968$ for (pseudo) first order and second order, respectively, using method A). The reaction order assessed with Method B is 1.94, which is very close to a second order. One explanation can be that in meat extracts, the interactions are more complicated/complex than with standard $\mathrm{Mb}$, as other scavengers could be present, so an apparent second-order decay is easier to determine even using Method A (which is less precise than Method B). Method B will be used further on. Nevertheless, the fitting should be replaced with a more significant equation in this case (Chi-Sqr $\left.=11.10, \mathrm{R}^{2}=0.9452\right)$, because this high deviation from a single-exponential equation proves once again that a second-order decay might be involved. A double-exponential equation could be helpful, as suggested in reference [54].

Nevertheless, the single-exponential fitting of pseudo first-order situations $\left(\mathrm{C}_{\mathrm{PON}}=\right.$ $\mathrm{C}_{0 \mathrm{PON}} \cdot \mathrm{e}-{ }^{\mathrm{kx}}$ ) determines $k_{\text {obs }}$, which allows us to detect the (apparent) second-order rate constants $\left(\mathrm{k}_{\mathrm{cat}}\right)$, for a larger concentration range of scavengers or other reactants involved (especially the concentration of the catalyzer, myoglobin, or other) [24,25]. The $\mathrm{k}_{\text {cat }}$ obtained from a linear fit of $k_{o b s}$ vs. catalyst concentration will refine our findings on second-order kinetics and improve the investigation of the scavenging effect of myoglobin over PON in meat extracts or other biological samples.

\subsubsection{Determination of Apparent Rate Constants and Half-Lives for the Decay of PON}

Molina et al. [30] describe the observed half-life $t_{1 / 2}=9.4 \pm 0.1 \mathrm{~s}$ for PBS $0.07 \mathrm{M}$, at $\mathrm{pH} 8$, for PON $250 \mu \mathrm{M}$. We have determined that apparent $\mathrm{k}=0.0086 \mathrm{~s}^{-1}$ with Method A and $\mathrm{k}=0.0078 \mathrm{~s}^{-1}$ with Method $\mathrm{B}$ (the apparent first-order decomposition rate constant), for PBS 0.1 M, at pH 9, for a concentration of $150 \mu \mathrm{M}\left(\mathrm{t}_{1 / 2}=252.12 \pm 2.97\right)$. As it can be seen, in the chosen conditions, $\mathrm{PON}$ is more stable than in the conditions described by Molina et al., mainly because of more alkaline $\mathrm{pH}$, more ionic strength in the buffer, and smaller concentrations of PON. Kissner et al. described this kind of behavior [31].

The decomposition of PON occurs faster at lower concentrations at $\mathrm{pH} \mathrm{9,} \mathrm{as} \mathrm{it}$ can be observed from the UV-Vis data in Table 3. The same conclusion can be drawn from our SPCE/CoPc developed method: PON $50 \mu \mathrm{M}$ will decay faster (reaction rate of $0.426 \times 10^{-6} \mathrm{~s}^{-1}$, using $\mathrm{t}_{1 / 2}=81.33 \mathrm{~s}$ ) than PON $150 \mu \mathrm{M}$ (reaction rate of $0.412 \times 10^{-6} \mathrm{~s}^{-1}$, using $\mathrm{t}_{1 / 2}=252.12 \mathrm{~s}$ ), where $\mathrm{k}=0.693 / \mathrm{t}_{1 / 2}$ and $\mathrm{r}=\mathrm{k}\left[\mathrm{C}_{\mathrm{PON}}\right]$. Reaction rates in the range of $10^{-6}$ for $50 \mu \mathrm{M}$ PON at $\mathrm{pH} 9$ are described by Kissner et al. [31], and this is in very good accordance with the data we obtained.

The myoglobin-mediated decay of $\mathrm{PON}$ is described as a second-order rate interaction. Most probably, the scavenging effect gives rise to ferrylmyoglobin $\left(\mathrm{MbFe}^{4+}=\mathrm{O}\right)$ with a rate constant of $4.6 \pm 0.2 \times 10^{4} \mathrm{M}^{-1} \mathrm{~s}^{-1}$, at $\mathrm{pH} 8.3$, in the absence of $\mathrm{CO}_{2}$, that will further react with PON with a rate constant of $1.2 \pm 0.2 \times 10^{4} \mathrm{M}^{-1} \mathrm{~s}^{-1}$ to form metMb [21]. The oxidation of redMb to metMb is not a stoichiometric reaction, as eight to 25 equiva- 
lents of PON are required for the oxidation reaction to be completed (depending on the absence or presence of $\mathrm{CO}_{2}$ ), as the natural decay of PON takes place at the same time. A 10-fold excess of PON is necessary for pseudo first-order conditions to be fulfilled. As the concentration of nitrite does not influence the interaction of myoglobin with peroxynitrite in a direct manner [21], our PON synthesized using the alkaline method is suitable for kinetic calculations (or otherwise saying, the decay of PON in the presence of myoglobin is a zero-order reaction in nitrite [2,21]).

The metMb scavenges $\mathrm{PON}$ at a lower rate than redMb or even than ferrylMb. MetMb catalyzes the isomerization of $\mathrm{PON}$ to nitrate, at $\mathrm{pH} 7$, at $20^{\circ} \mathrm{C}$, with a rate of $29,000 \pm 100 \mathrm{M}^{-1} \mathrm{~s}^{-1}$, and an iron $\mathrm{Fe}^{3+}$ core of metMb is involved in this process. The $\mathrm{k}$ values decrease with increasing $\mathrm{pH}$; thus, the decay rate is expected to be smaller for $\mathrm{pH} 9$ [24]. So, scavenging $\mathrm{PON}$ with metMb is less effective at $\mathrm{pH} 8$ (or above) than at biological $\mathrm{pH}$, with a PON decay rate constant $\mathrm{k}$ of $2700 \pm 30 \mathrm{M}^{-1} \mathrm{~s}^{-1}$, for $\mathrm{pH} 8,0.1 \mathrm{M}$ PBS, for $100 \mu \mathrm{M}$ of PON, in the absence of $\mathrm{CO}_{2}$, at $20^{\circ} \mathrm{C}$ [24]. In our case, at pH 9, PBS $0.1 \mathrm{M}, 25^{\circ} \mathrm{C}$, the apparent $\mathrm{k}$ value of the reaction of $15 \mu \mathrm{M}$ myoglobin and $50 \mu \mathrm{M}$ PON was calculated to be $311.87 \pm 7.96 \mathrm{M}^{-1} \mathrm{~s}^{-1}$ using Method $\mathrm{B}$ (where deviations from pseudo first order are second order). This value is lower than the value that Herold et al. obtained, which is probably due to the $\mathrm{pH}$ values and the temperature difference. As far as our knowledge goes, the kinetics of this exact decay conditions were not described in the literature before. Nevertheless, more PON or target molecule (myoglobin) concentrations are to be varied for refining better apparent second orders.

The scavenging was evaluated by comparing the decomposition rate of $\mathrm{PON}$ in the absence and in the presence of myoglobin (from both standard and meat extracts). The standard $\mathrm{Mb}$ decreased the half-life on PON from 81 to $65 \mathrm{~s}$ (for $50 \mu \mathrm{M}$ ) and from 250 to $88 \mathrm{~s}$ (for $150 \mu \mathrm{M}$ ), thus increasing the rate of decomposition in both cases. As in accordance with the UV-Vis spectra (Figure 12a) of metMb incubated with $50 \mu \mathrm{M}$ of PON, the scavenging effect of $15 \mu \mathrm{M}$ metMb with $50 \mu \mathrm{M}$ PON is not very effective, and the calculated $t_{1 / 2}$ values are in accordance with the UV-Vis data (with less $10 \%$ error values between the two methods). This is because the number of equivalents of PON (here around 3) were not sufficient to oxidize myoglobin. When we increase the number of equivalents to $10(150 \mu \mathrm{M}$ PON), the scavenging effect can be observed with both UV-Vis and FIA-EC.

The scavenging effect of the myoglobin from meat was stronger than we initially thought (as we expected the concentration of $\mathrm{Mb}$ to be similar to the standard $\mathrm{Mb}$ ), with a $\mathrm{t}_{1 / 2}$ of $19.77 \pm 0.10 \mathrm{~s}$. Even if we estimated the concentration of myoglobin to be around $15 \mu \mathrm{M}$ in the extracted meat (diluted 10 times in PBS pH 9), when we compare the decay constants of $\mathrm{PON}$, we can observe that the standard $\mathrm{Mb}$ has a lower apparent $\mathrm{k}$ constant $\left(311.87 \pm 7.96 \mathrm{M}^{-1} \mathrm{~s}^{-1}\right)$ than the meat extract $\left(891.76 \pm 220.54 \mathrm{M}^{-1} \mathrm{~s}^{-1}\right)$; thus, it has a higher half-life. Nevertheless, this may come from different oxidation states of the myoglobin in meat extract, and the presence of other possible scavengers in meat is not excluded. Other studies including varying concentrations of PON, myoglobin, and/or other catalysts from meat or other biological samples are still to be performed further.

\section{Conclusions}

Our label-free electrochemical method proposes a cobalt phthalocyanine deposition on the screen-printed carbon electrode (SPCE/CoPc) for the direct detection of peroxynitrite via electrocatalyzed reduction. This method is simple, sensitive, highly selective, rapid, and cost-effective. A simple flow injection system based on amperometric detection at potentials near $+0.1 \mathrm{~V}$ was designed for PON determination, bringing the possibility for the automation and fast-response measurements. CA (chronoamperometry) was used to establish that changing the applied potential, the sensing mechanism of the electrode is changing/becomes easier to distinguish: the oxidation of PON occurs near $0.07 \mathrm{~V}$ and the reduction occurs near $0.05 \mathrm{~V}$. At those low redox potentials $(60 \mathrm{mV})$, the most important interfering species are less likely to appear, especially for the reduction potential. 
We optimized different parameters (flow rate, reduction potential, the quantity of deposited CoPc on the surface of the electrode, determined surface coverage etc.), and we suggested a mechanism that described the electro-reduction of PON, involving two electrons, based on the electrochemical characterization of the electrodes. We also determined that the electrochemical reactions taking place at the surface of the electrode are not simply diffusion-controlled ones, and other processes such as adsorption, ligand-based processes may take place. Interfering species were studied at a 5-fold concentration compared to PON, and only hydrogen peroxide responded with a very low sensitivity and under an electro-oxidation catalyzed mechanism, not influencing our PON detection.

Compared to the literature, this is one of the few articles based on the electro-catalyzed reduction of PON. Even though we obtained good sensitivity (with an LOD of $0.4 \mu \mathrm{M}$ compared to $1.9 \mathrm{nM}$ [14] and $1.0 \mathrm{nM}$ [15], but higher than $5 \mu \mathrm{M}$ [16]), we achieved a much better selectivity against all the important interfering species (ascorbic acid, hydrogen peroxide, nitrate, and nitrite) at biological concentrations.

The optimized SPCE/CoPc calibration helped us monitor and quantify PON and the reaction between peroxynitrite and myoglobin. The literature presents the fact that the $\mathrm{PON}$ to redMb ratio must be 1:10 for efficient scavenging and that metMb is less efficient in scavenging PON (as the metal center is already oxidized) [24,52]. The scavenging of $\mathrm{PON}$ with myoglobin (in the form of metMb and redMb) decreases the amount of PON, and this decrease was measured/quantified with our SPCE/CoPc electrode. As the UV-Vis technique cannot be used to study the interaction with myoglobin (as the protein peak at $280 \mathrm{~nm}$ interferes with the PON peak at $302 \mathrm{~nm}$ ), our FIA-EC method is an alternative technique that is able to study the scavenging effect of myoglobin from meat extracts toward peroxynitrite. The similarity of absorption spectra, especially in the UV zone, corresponding to redMb and meat extracts after incubation with PON, proving once again that $\mathrm{PON}$ is decomposed during the irreversible oxidation of redMb to metMb.

We propose a simple method that has great impact on the PON sensor choice, as it can be used to quantify PON in complex media (such as meat samples) but also to study the kinetics of PON decay. We have also demonstrated that one can study the interaction of PON with different forms of myoglobin. Kinetic studies were also performed and correlated with the literature to study the scavenging effect. Meat extracts scavenged better $\mathrm{PON}$, which was probably due to different forms of $\mathrm{Mb}$ and the possibility of another scavenger. The scavenging effect is a second-order decay rate (when PON is not in excess, when pseudo first orders apply), and the rate constants were determined.

Our study for the kinetics should be regarded more as an alternative possible method ("proof of concept") for studying the interaction between PON and myoglobin using the FIA-EC method than a finalized kinetic study. The kinetic parameters obtained with both proposed kinetic methods (A and B) were in good correlation with each other. We can conclude that our FIA-EC method is precise enough for further studying the interaction of PON with scavengers. Evaluation of decay order for the interactions is impossible with the classical static UV-Vis method (that also has a low sensitivity toward PON, as an absorbance of 0.08 a.u. corresponds to $50 \mu \mathrm{M}$ PON).

A further research direction is to use the already described hybrid materials (CoPcgraphene) to increase the solubility of the hybrid material in aqueous solvents and electron transfer at the surface of the electrode. The electroactive film could be also deposited on micro-electrodes to be used for the detection of PON in physiological conditions.

Author Contributions: Conceptualization, M.D. and I.S.H.; methodology I.S.H., investigation, I.S.H. and D.C.-A.; project administration, M.D. and F.O.; supervision, M.D. and F.O.; validation, M.D., visualization, M.D. and I.S.H., writing-original draft preparation, I.S.H.; writing-review and editing, M.D., I.S.H., D.C.-A. and F.O. All authors have read and agreed to the published version of the manuscript. 
Funding: This work was supported by Romanian National Authority for Scientific Research and Innovation, CCDI-UEFISCDI, Project PN-II-ID-PCE-2011-3-1076 and project ERANET-MANUNET-NITRISENS, contract no. 216/2020 within PNCDI III. The authors also acknowledge the financial support to Ministry of Research and Innovation, Nucleu Programme ChemEmergent, Project PN.19.23.01.01—Smart-Bi.

Institutional Review Board Statement: Not applicable.

Informed Consent Statement: Not applicable.

Acknowledgments: The authors are grateful to Sanda Doncea for FTIR measurements and Alina Vasilescu for all the advices and the cobalt phthalocyanine.

Conflicts of Interest: The authors declare no conflict of interest. The funders had no role in the design of the study; in the collection, analyses, or interpretation of data; in the writing of the manuscript, or in the decision to publish the results.

\section{References}

1. Hosu, I.S.; Constantinescu-Aruxandei, D.; Oancea, F.; Doni, M. Studying the Reaction of Peroxynitrite with Myoglobin for Meat Extract Samples Using Cobalt Phthalocyanine-Modified Screen-Printed Carbon Electrodes and a Flow Injection Analysis System. Proceedings 2020, 60, 46. [CrossRef]

2. Exner, M.; Herold, S. Kinetic and mechanistic studies of the peroxynitrite-mediated oxidation of oxymyoglobin and oxyhemoglobin. Chem. Res. Toxicol. 2000, 13, 287-293. [CrossRef]

3. Vasilescu, A.; Vezeanu, A.; Liu, Y.; Hosu, I.S.; Worden, R.M.; Peteu, S.F. Meat Freshness: Peroxynitrite's Oxidative Role, Its moltural Scavengers, and New Measuring Tools. In Instrumental Methods for the Analysis and Identification of Bioactive Molecules; Jayprakasha, G.K., Patil, B.S., Pellati, F., Eds.; American Chemical Society: Washington, DC, USA, 2014; pp. 303-332.

4. Brannan, R.G.; Decker, E.A. Peroxynitrite-induced oxidation of lipids: Implications for muscle foods. J. Agric. Food Chem. 2001, 49, 3074-3079. [CrossRef] [PubMed]

5. Jeong, J.Y.; Kim, G.D.; Yang, H.S.; Joo, S.T. Pigments and Color of Muscle Foods; CRC Press: Boca Raton, FL, USA, $2014 ;$ pp. 44-61.

6. Møller, J.K.S.; Skibsted, L.H. Myoglobins: The link between discoloration and lipid oxidation in muscle and meat. Quim. Nova 2006, 29, 1270-1278. [CrossRef]

7. Szunerits, S.; Peteu, S.; Boukherroub, R. CHAPTER 4 Peroxynitrite-Sensitive Electrochemically Active Matrices. In Peroxynitrite Detection in Biological Media: Challenges and Advances; The Royal Society of Chemistry: Cambridge, UK, 2016 ; pp. 63-77.

8. Li, M.; Gong, X.; Li, H.-W.; Han, H.; Shuang, S.; Song, S.; Dong, C. A fast detection of peroxynitrite in living cells. Anal. Chim. Acta 2020, 1106, 96-102. [CrossRef] [PubMed]

9. Wada, M.; Kira, M.; Kido, H.; Ikeda, R.; Kuroda, N.; Nishigaki, T.; Nakashima, K. Semi-micro flow injection analysis method for evaluation of quenching effect of health foods or food additive antioxidants on peroxynitrite. Luminescence 2011, 26, 191-195. [CrossRef] [PubMed]

10. Ruzicka, J.; Ruzicka, J. Flow injection analysis-A survey of its potential as solution handling and data gathering technique in chemical research and industry. Z. Anal. Chem. 1988, 329, 653-655. [CrossRef]

11. Hosu, I.S.; Wang, Q.; Vasilescu, A.; Peteu, S.F.; Raditoiu, V.; Railian, S.; Zaitsev, V.; Turcheniuk, K.; Wang, Q.; Li, M.; et al. Cobalt phthalocyanine tetracarboxylic acid modified reduced graphene oxide: A sensitive matrix for the electrocatalytic detection of peroxynitrite and hydrogen peroxide. RSC Adv. 2015, 5, 1474-1484. [CrossRef]

12. Cortes, J.S.; Granados, S.G.; Ordaz, A.A.; Jimenez, J.A.L.; Griveau, S.; Bedioui, F. Electropolymerized manganese tetraaminophthalocyanine thin films onto platinum ultramicroelectrode for the electrochemical detection of peroxynitrite in solution. Electroanalysis 2007, 19, 61-64. [CrossRef]

13. Oprea, R.; Peteu, S.F.; Subramanian, P.; Qi, W.; Pichonat, E.; Happy, H.; Bayachou, M.; Boukherroub, R.; Szunerits, S. Peroxynitrite activity of hemin-functionalized reduced graphene oxide. Analyst 2013, 138, 4345-4352. [CrossRef]

14. Koh, W.C.A.; Son, J.I.; Choe, E.S.; Shim, Y.-B. Electrochemical Detection of Peroxynitrite Using a Biosensor Based on a Conducting Polymer-Manganese Ion Complex. Anal. Chem. 2010, 82, 10075-10082. [CrossRef]

15. Mason, R.; Jacob, R.; Corbalan, J.; Szczesny, D.; Matysiak, K.; Malinski, T. The favorable kinetics and balance of nebivololstimulated nitric oxide and peroxynitrite release in human endothelial cells. BMC Pharmacol. Toxicol. 2013, 14, 48. [CrossRef] [PubMed]

16. Hosu, I.S.; Constantinescu-Aruxandei, D.; Jecu, M.-L.; Oancea, F.; Badea Doni, M. Peroxynitrite Sensor Based on a Screen Printed Carbon Electrode Modified with a Poly(2,6-dihydroxynaphthalene) Film. Sensors 2016, 16, 1975. [CrossRef] [PubMed]

17. Boni, A.C.; Wong, A.; Dutra, R.A.F.; Sotomayor, M.D.T. Cobalt phthalocyanine as a biomimetic catalyst in the amperometric quantification of dipyrone using FIA. Talanta 2011, 85, 2067-2073. [CrossRef] [PubMed]

18. Angnes, L.; Azevedo, C.M.N.; Araki, K.; Toma, H.E. Electrochemical detection of NADH and dopamine in flow analysis based on tetraruthenated porphyrin modified electrodes. Anal. Chim. Acta. 1996, 329, 91-95. [CrossRef]

19. Channon, R.B.; Joseph, M.B.; Bitziou, E.; Bristow, A.W.T.; Ray, A.D.; Macpherson, J.V. Electrochemical Flow Injection Analysis of Hydrazine in an Excess of an Active Pharmaceutical Ingredient: Achieving Pharmaceutical Detection Limits Electrochemically. Anal. Chem. 2015, 87, 10064-10071. [CrossRef] 
20. Santos, A.M.; Silva, T.A.; Vicentini, F.C.; Fatibello-Filho, O. Flow injection analysis system with electrochemical detection for the simultaneous determination of nanomolar levels of acetaminophen and codeine. Arab. J. Chem. 2020, 13, 335-345. [CrossRef]

21. Herold, S.; Exner, M.; Boccini, F. The mechanism of the peroxynitrite-mediated oxidation of myoglobin in the absence and presence of carbon dioxide. Chem. Res. Toxicol. 2003, 16, 390-402. [CrossRef]

22. Ascenzi, P.; Marinis, E.D.; Masi, A.d.; Ciaccio, C.; Coletta, M. Peroxynitrite scavenging by ferryl sperm whale myoglobin and human hemoglobin. Biochem. Biophys. Res. Commun. 2009, 390, 27-31. [CrossRef]

23. Connolly, B.J.; Brannan, R.G.; Decker, E.A. Potential of peroxynitrite to alter the color of myoglobin in muscle foods. J. Agric. Food Chem. 2002, 50, 5220-5223. [CrossRef] [PubMed]

24. Herold, S.; Shivashankar, K. Metmyoglobin and methemoglobin catalyze the isomerization of peroxynitrite to nitrate. Biochemistry 2003, 42, 14036-14046. [CrossRef] [PubMed]

25. Kalinga, S. Peroxynitrite-Induced Modifications of Myoglobin: A Kinetic and Mechanistic Study. Ph.D. Thesis, ETH Zurich, Zürich, Switzerland, 2005.

26. Connolly, B.J.; Decker, E.A. Peroxynitrite induced discoloration of muscle foods. Meat Sci. 2004, 66, 499-505. [CrossRef]

27. Robinson, K.M.; Beckman, J.S. Synthesis of Peroxynitrite from Nitrite and Hydrogen Peroxide. In Methods in Enzymology; Academic Press: Cambridge, MA, USA, 2005; Volume 396, pp. 207-214. [CrossRef]

28. Badea, M.; Amine, A.; Benzine, M.; Curulli, A.; Moscone, D.; Lupu, A.; Volpe, G.; Palleschi, G. Rapid and Selective Electrochemical Determination of Nitrite in Cured Meat in the Presence of Ascorbic Acid. Microchim. Acta 2004, 147, 51-58. [CrossRef]

29. Herold, S. Kinetic and spectroscopic characterization of an intermediate peroxynitrite complex in the nitrogen monoxide induced oxidation of oxyhemoglobin. FEBS Lett. 1998, 439, 85-88. [CrossRef]

30. Molina, C.; Kissner, R.; Koppenol, W.H. Decomposition kinetics of peroxynitrite: Influence of pH and buffer. Dalton Trans. 2013, 42, 9898-9905. [CrossRef] [PubMed]

31. Kissner, R.; Koppenol, W.H. Product Distribution of Peroxynitrite Decay as a Function of $\mathrm{pH}$, Temperature, and Concentration. J. Am. Chem. Soc. 2002, 124, 234-239. [CrossRef]

32. Levine, I. Physical Chemistry; McGraw-Hill Education: New York, NY, USA, 2009.

33. Ischiropoulos, H.; Al-Mehdi, A.B. Peroxynitrite-mediated oxidative protein modifications. FEBS Lett. 1995, 364, $279-282$. [CrossRef]

34. Carballal, S.; Bartesaghi, S.; Radi, R. Kinetic and mechanistic considerations to assess the biological fate of peroxynitrite. Biochim. Biophys. Acta Gen. Subj. 2014, 1840, 768-780. [CrossRef] [PubMed]

35. Herold, S.; Shivashankar, K.; Mehl, M. Myoglobin Scavenges Peroxynitrite without Being Significantly Nitrated. Biochemistry 2002, 41, 13460-13472. [CrossRef]

36. Dashteh, M.; Safaiee, M.; Baghery, S.; Zolfigol, M.A. Application of cobalt phthalocyanine as a nanostructured catalyst in the synthesis of biological henna-based compounds. Appl. Organomet. Chem. 2019, 33, e4690. [CrossRef]

37. Kumar, P.; Kumar, A.; Sreedhar, B.; Sain, B.; Ray, S.S.; Jain, S.L. Cobalt Phthalocyanine Immobilized on Graphene Oxide: An Efficient Visible-Active Catalyst for the Photoreduction of Carbon Dioxide. Chem. A Eur. J. 2014, 20, 6154-6161. [CrossRef]

38. Tackley, D.R.; Dent, G.; Ewen Smith, W. IR and Raman assignments for zinc phthalocyanine from DFT calculations. Phys. Chem. Chem. Phys. 2000, 2, 3949-3955. [CrossRef]

39. Szybowicz, M.; Bała, W.; Dümecke, S.; Fabisiak, K.; Paprocki, K.; Drozdowski, M. Temperature and orientation study of cobalt phthalocyanine CoPc thin films deposited on silicon substrate as studied by micro-Raman scattering spectroscopy. Thin Solid Film. 2011, 520, 623-627. [CrossRef]

40. Aroca, R.; Pieczonka, N.; Kam, A.P. Surface-enhanced Raman scattering and SERRS imaging of phthalocyanine mixed films. J. Porphyr. Phthalocyanines 2001, 5, 25-32. [CrossRef]

41. Shih, Y.; Zen, J.M.; Kumar, A.S.; Chen, P.Y. Flow injection analysis of zinc pyrithione in hair care products on a cobalt phthalocyanine modified screen-printed carbon electrode. Talanta 2004, 62, 912-917. [CrossRef]

42. Fotouhi, L.; Hashkavayi, A.B.; Heravi, M.M. Electrochemical behaviour and voltammetric determination of sulphadiazine using a multi-walled carbon nanotube composite film-glassy carbon electrode. J. Exp. Nanosci. 2013, 8, 947-956. [CrossRef]

43. Foster, C.W.; Pillay, J.; Metters, J.P.; Banks, C.E. Cobalt phthalocyanine modified electrodes utilised in electroanalysis: Nanostructured modified electrodes vs. bulk modified screen-printed electrodes. Sensors 2014, 14, 21905-21922. [CrossRef] [PubMed]

44. Bedioui, F.; Quinton, D.; Griveau, S.; Nyokong, T. Designing molecular materials and strategies for the electrochemical detection of nitric oxide, superoxide and peroxynitrite in biological systems. Phys. Chem. Chem. Phys. 2010, 12, 9976-9988. [CrossRef]

45. Storkey, C.; Pattison, D.I.; Ignasiak, M.T.; Schiesser, C.H.; Davies, M.J. Kinetics of reaction of peroxynitrite with selenium- and sulfur-containing compounds: Absolute rate constants and assessment of biological significance. Free Radic. Biol. Med. 2015, 89, 1049-1056. [CrossRef]

46. Møinichen, C. Microfluidic Flow Cells for Studies of Electrochemical Reactions. Master's Thesis, Institutt for Materialteknologi, Oslo, Norway, 2012.

47. Ai, F.; Chen, H.; Zhang, S.H.; Liu, S.Y.; Wei, F.; Dong, X.Y.; Cheng, J.K.; Huang, W.H. Real-time monitoring of oxidative burst from single plant protoplasts using microelectrochemical sensors modified by platinum nanoparticles. Anal. Chem. 2009, 81, 8453-8458. [CrossRef]

48. Amatore, C.; Arbault, S.; Bruce, D.; de Oliveira, P.; Erard, M.; Vuillaume, M. Characterization of the electrochemical oxidation of peroxynitrite: Relevance to oxidative stress bursts measured at the single cell level. Chem.Eur. J. 2001, 7, 4171-4179. [CrossRef] 
49. Kissner, R.; Nauser, T.; Bugnon, P.; Lye, P.G.; Koppenol, W.H. Formation and properties of peroxynitrite as studied by laser flash photolysis, high-pressure stopped-flow technique, and pulse radiolysis. Chem. Res. Toxicol. 1998, 11, 1285-1292. [CrossRef]

50. Kirsch, M.; Korth, H.-G.; Wensing, A.; Sustmann, R.; de Groot, H. Product formation and kinetic simulations in the pH range 1-14 account for a free-radical mechanism of peroxynitrite decomposition. Arch. Biochem. Biophys. 2003, 418, 133-150. [CrossRef] [PubMed]

51. Ascenzi, P.; De Simone, G.; Tundo, G.R.; Platas-Iglesias, C.; Coletta, M. Ferric nitrosylated myoglobin catalyzes peroxynitrite scavenging. J. Biol. Inorg. Chem. 2020, 25, 361-370. [CrossRef]

52. Rehmann, F.-J. Mechanistic Studies of the Nitrogen Monoxide-and Nitrite-Mediated Reduction of Ferryl Myoglobin and Ferryl Hemoglobin. Ph.D. Thesis, ETH Zürich, Zürich, Switzerland, 2002.

53. Tang, J.; Faustman, C.; Hoagland, T.A. Krzywicki Revisited: Equations for Spectrophotometric Determination of Myoglobin Redox Forms in Aqueous Meat Extracts. J. Food Sci. 2004, 69, C717-C720. [CrossRef]

54. Carballal, S.; Cuevasanta, E.; Yadav, P.K.; Gherasim, C.; Ballou, D.P.; Alvarez, B.; Banerjee, R. Kinetics of Nitrite Reduction and Peroxynitrite Formation by Ferrous Heme in Human Cystathionine $\beta$-Synthase*. J. Biol. Chem. 2016, 291, 8004-8013. [CrossRef] 